\title{
EL GÉNERO RUEHSSIA (APOCYNACEAE) EN LA ARGENTINA: FILOGENIA, NUEVAS COMBINACIONES Y NUEVOS REGISTROS
}

\author{
Héctor A. Keller ${ }^{1}$, Sigrid Liede-Schumann², Alessandro Rapini ${ }^{3}$ \& Sergio Cáceres Moral ${ }^{1}$
}

\author{
${ }^{1}$ Instituto de Botánica del Nordeste, Casilla de Correo 209, 3400 Corrientes, Argentina; kellerhector@hotmail.com \\ (autor corresponsal). \\ ${ }^{2}$ University of Bayreuth, Universitätsstrasse 30, 95440 Bayreuth, Germany. \\ ${ }^{3}$ Programa de Pós-graduação em Botânica, Departamento de Ciências Biológicas, Universidade Estadual de Feira de \\ Santana, Av. Transnordestina s/n, Novo Horizonte, Feira de Santana, Bahia, 44036-900, Brasil.
}

\begin{abstract}
Keller, H. A.; S. Liede-Schumann; A. Rapini \& S. Cáceres Moral. 2020. The genus Ruehssia (Apocynaceae) from Argentina: phylogeny, new combinations and new records. Darwiniana, nueva serie 8(2): 414-437.

Ruehssia was recently reestablished to classify all American species of the tribe Marsdenieae. Here, we provide a revision of the genus in Argentina, with an identification key, comments, a distribution map, and images of all species. The phylogenetic position of all species has been assessed using chloroplast and nuclear DNA sequences. We recognize six species. Besides $R$. altissima and $R$. macrophylla, we include two new records, $R$. hilariana and $R$. brasiliensis, and propose two new combinations in the genus, $R$. castillonii (Lillo ex T. Mey.) H.A. Keller \& Liede and R. tressensiae (S.A. Cáceres \& Morillo) H.A. Keller \& Liede. Ruehssia montana and R. ulei, previously reported to Argentina, do not occur in the country.
\end{abstract}

Keywords. Asclepiadoideae; Marsdenia; Marsdenieae; taxonomy.

Resumen. Keller, H. A.; S. Liede-Schumann; A. Rapini \& S. Cáceres Moral. 2020. El género Ruehssia (Apocynaceae) en la Argentina: filogenia, nuevas combinaciones y nuevos registros. Darwiniana, nueva serie 8(2): 414-437.

Ruehssia se restableció recientemente para clasificar a todas las especies americanas de la tribu Marsdenieae. Aquí, ofrecemos una revisión del género en la Argentina, con una clave de identificación, comentarios, un mapa de distribución e imágenes de todas las especies. La posición filogenética de todas las especies se ha evaluado utilizando secuencias de ADN nuclear y cloroplástico. Reconocemos seis especies. Además de $R$. altissima y $R$. macrophylla, incluimos dos nuevos registros, $R$. hilariana y $R$. brasiliensis, y proponemos dos nuevas combinaciones en el género, $R$. castillonii (Lillo ex T. Mey.) H.A. Keller \& Liede y R. tressensiae (S.A. Cáceres y Morillo) H.A. Keller \& Liede. Ruehssia montana y $R$. ulei, previamente citadas para la Argentina, no habitan en el país.

Palabras clave. Asclepiadoideae; Marsdenia; Marsdenieae; taxonomía.

\section{INTRODUCCIÓN}

Apocynaceae es una familia predominantemente pantropical, con relativamente pocos géneros que alcanzan regiones templadas australes o boreales. $\mathrm{La}$ subfamilia Asclepiadoideae es la más diversificada con 181 géneros que se distribuyen en 5 tribus, dos de las cuales cuentan con representantes en el nuevo mundo, Asclepiadeae Duby y Marsdenieae Benth.
La tribu Marsdenieae comprende hierbas, volubles, epífitas y epipétricas con polinias erectas; cuenta con 26 géneros principalmente distribuidos en el paleotrópico y Australia, con un sólo género en el neotrópico (Endress et al., 2018).

Marsdenia R. Br., un género cuyos límites aún no son del todo claros, se ha considerado durante mucho tiempo como el único linaje de Asclepiadoideae de Américaconpoliniaserectas(Rapinietal.,2003;2007). 
Sin embargo, estudios filogenéticos basados en datos moleculares indican que las especies americanas son monofiléticas, pero no estrechamente relacionadas con $M$. tinctoria $\mathrm{R}$. Br., la especie tipo del género y nativa de Asia, por lo cual Espírito Santo et al. (2019) han restablecido Ruehssia H. Karst. para clasificar al clado americano de Marsdenieae.

Ruehssia fue válidamente publicada hace más de un siglo y medio por Karsten (1849), quien describió este taxón, tres especies nuevas y estableció la combinación para $R$. macrophylla (Humb. \& Bonpl. ex Schult.) H. Karst., especie recientemente seleccionada como lectotipo del género por Espírito Santo et al. (2019). El género comprende unas 110 especies americanas (la mayoría incluidas aún en Marsdenia) e incluye plantas volubles, arbustivas, subarbustivas, erectas o postradas. Las inflorescencias son umbeliformes, glomeruladas o racemiformes, raramente escorpioides, fasciculadas o paniculadas, a diferencia de la especie típica de Marsdenia que se caracteriza por presentar inflorescencias tirsoideas alargadas.

Espírito Santo et al. (2019) establecieron sólo las nuevas combinaciones de Ruehssia correspondientes a las especies distribuidas en Brasil. Las combinaciones para las especies que no ocurren en Brasil, pero sí en nuestro país, se efectúan en el presente trabajo y las combinaciones para otras especies americanas se publicarán en próximas contribuciones (Liede et al., en prep.; Liede \& Keller., en prep.).

En la Argentina se han citado hasta el presente seis especies de Marsdenieae: Marsdenia castillonii Lillo ex T. Mey. (Meyer, 1944), M. tressensiae S.A. Cáceres \& Morillo (Cáceres Moral, 1993), Ruehssia altissima (Jacq.) F. Esp. Santo \& Rapini (Meyer, 1944), la especie típica del género $R$. macrophylla (Humb. \& Bonpl. ex Schult.) H. Karst. (Meyer, 1947), $R$. montana (Malme) F. Esp. Santo \& Rapini (Tressens et al., 2008) y R. ulei (Schltr. \& W. Rothe) F. Esp. Santo \& Rapini (Meyer, 1944). El objetivo de la presente contribución es establecer las necesarias nuevas combinaciones para clasificar a las dos primeras especies dentro del género Ruehssia, confirmar o corregir la identidad de las especies que habitan en la Argentina y evaluar la posición filogenética de las especies argentinas en el contexto más amplio de Ruehssia en las Américas para vislumbrar si estas especies están estrechamente relacionadas entre sí, o si son representantes de varios linajes.
Además, se brinda información sobre aspectos morfológicos y ecológicos de cada especie, un análisis filogenético basado en ADN nuclear y cloroplástico, una clave de identificación, un mapa de distribución e imágenes de todas las especies.

\section{MATERIALES Y MÉTODOS}

Para obtener las imágenes empleadas en el proceso de estudio del material de las especies aquí tratadas, se utilizaron una cámara fotográfica de alta resolución Sony DSC-HX400V y una lupa estereoscópica Zeiss Stemi DV4.

Con el fin de determinar las posiciones filogenéticas de las especies de Ruehssia argentinas, en primer lugar, se realizó la extracción de ADN total a partir de hojas frescas conservadas en sílica o de fragmentos de hojas tomadas de especímenes de herbario, utilizando el kit de extracción DNeasy Plant Mini Kit (Qiagen, Hilden, Alemania), siguiendo las instrucciones del fabricante. Se amplificaron y secuenciaron cinco marcadores cloroplásticos y cuatro marcadores nucleares. Los cebadores y protocolos de PCR para los espaciadores plastidiales trnT-trnL y trnL-trnF y el intrón trnL corresponden a Taberlet et al. (1991). El intrón trnL y el espaciador intergénico trnL-trnF se amplificaron como un único fragmento, usando los cebadores c y f. El intrón rps 16 se amplificó según Liede-Schumann et al. (2005), utilizando el par de cebadores rps 16-1F y rps 16-2R. El espaciador intergénico trnH-psbA se amplificó con los cebadores y el protocolo diseñados por Sang et al. (1997) y el espaciador psbD-trnT, de acuerdo con Espírito Santo et al. (2019). Los marcadores nucleares comprenden el ITS (siglas en inglés de Espaciador Transcrito Interno) y el ETS (Espaciador Transcrito Externo), amplificados según el protocolo de Espírito Santo et al. (2019), así como dos marcadores nucleares adicionales de copia única, At2g06530a y At2g34620b, secuenciados de acuerdo con los cebadores y el protocolo brindados por Straub et al. (2011).

Un total de 167 secuencias parciales fueron creadas para este estudio, se secuenciaron, por primera vez, 27 accesiones correspondientes a 22 especies. Las secuencias de las accesiones y especies restantes se obtuvieron de GenBank, utilizando principalmente secuencias de estudios previos de los autores del 
presente trabajo, y para cuatro especies, se agregaron marcadores adicionales a secuencias previamente existentes. Se incluyeron en el análisis únicamente las accesiones para las cuales había al menos dos secuencias parciales disponibles; dos muestras tenían solo dos secuencias parciales, y el promedio fue de 4,6 secuencias parciales por accesión.

Se ensambló una matriz de 63 accesiones correspondientes a 54 especies americanas de Marsdenieae: 40 accesiones (35 taxones) de América del Sur, 13 accesiones (12 taxones) de América Central y 10 accesiones (7 taxones) del Caribe. Como grupo externo, se utilizaron cuatro especies de Marsdenieae de África Occidental: dos de Anisopus N.E. Br., M. exellii Norman y $M$. magniflora P.T. Li, que habían sido recuperadas como hermanas de Ruehssia en una matriz más grande (Liede-Schumann, resultados no publicados). Los ejemplares de herbario, autores de especies y números de secuencia se detallan en el Apéndice.

Las secuencias de cada marcador se alinearon con el paquete MAFFT (Katoh \& Standley, 2013) dentro de Mesquite (Maddison \& Maddison, 2019) y las alineaciones resultantes se corrigieron manualmente. Para el caso de las secuencias de trnH-psbA que contenían una cantidad considerable de posiciones ambiguamente alineadas, éstas fueron eliminadas mediante GBLOCKS (Talavera \& Castresana, 2007) ejecutado en el servidor NGPhylogeny.fr (https://ngphylogeny.fr; Lemoine et al., 2019). La alineación completa está disponible en TreeBase (Piel et al., 2009; Vos et al., 2012) con el Número de Estudio S26235.

Para el conjunto de datos total, y por separado para una matriz que contiene solo ADNcp o solo ADN nuclear, aplicamos la inferencia de árbol de máxima verosimilitud o "maximum likelihood" (ML) y el análisis no paramétrico bootstrapping (BS) utilizando RAxML v. 8.2.10 (Stamatakis, 2014), tal como está disponible en la plataforma CIPRES (Miller et al., 2010). Este análisis implementa un modelo de sustitución de nucleótidos reversible en tiempo general (Rodríguez et al., 1990). No se encontraron discordancias incompatibles entre el conjunto de datos nucleares y el plastidial; sin embargo, los valores de soporte para ambos conjuntos de datos fueron muy bajos (resultados no mostrados). Por lo tanto, todos los análisis posteriores se llevaron a cabo utilizando el conjunto de datos combinado.
El conjunto de datos total fue analizado bajo el criterio de Inferencia Bayesiana (IB), ejecutado en MrBayes 3.2.2 (Huelsenbeck \& Ronquist, 2001; Ronquist \& Huelsenbeck, 2003) en la plataforma CIPRES (Miller et al., 2010). Se realizaron dos corridas independientes simultáneas con cuatro cadenas cada una (una fría y tres calientes). Las cadenas se ejecutaron durante 10 millones de generaciones, comenzando con un árbol aleatorio y muestreando un árbol cada 1000 generaciones. La inspección de los parámetros de las dos ejecuciones independientes se efectuó con Tracer v. 1.7 (Rambaut et al., 2018) indicando convergencia después de 1 millón de generaciones. Los primeros 5000 árboles de cada corrida fueron descartados y los 10000 árboles restantes se resumen en un árbol de consenso de $50 \%$ de mayoría, con probabilidades posteriores (PP) como una estimación del soporte para los nodos del árbol. Todas las particiones se desvincularon, los parámetros se estimaron independientemente y se sometieron a cuatro ejecuciones independientes simultáneas. Los modelos de sustitución de nucleótidos se establecieron en GTR + G para todas las particiones, con una proporción de sitios invariables (+ I) para rps 16 e ITS, siguiendo los resultados de ModelTest-NG (Darriba et al., 2020) en la plataforma CIPRES (Miller et al., 2010).

\section{RESULTADOS}

Ruehssia se recuperó con un buen soporte como monofilético (BS $=77 \%$, PP =99\%), y R. sprucei (W. Rothe) F. Esp. Santo \& Rapini, de la Amazonía de Brasil, Colombia y Venezuela, se recuperó con un buen soporte $(\mathrm{BS}=73 \%, \mathrm{PP}=93 \%)$ como hermana de todas las demás especies del género (Fig. 1).

El resto de las especies se divide en dos clados, uno centroamericano con bajo soporte (BS $<50 \%$, PP $=87 \%$ ), en el que se agrupan las especies caribeñas con soporte moderado (BS $=77 \%, \mathrm{PP}=92 \%$ ), $\mathrm{y}$ otro predominantemente sudamericano ( $\mathrm{BS}<50 \%, \mathrm{PP}=93 \%$ ), que a $\mathrm{su}$ vez se divide en dos subclados. El primero de estos subclados está bien respaldado $(\mathrm{BS}=76 \%$, $\mathrm{PP}=99 \%)$ y es casi exclusivamente brasileño, con $R$. hilariana (E. Fourn.) F. Esp. Santo \& Rapini como hermana del resto de las especies. 
H. A. KELLER ET AL. Ruehssia (Apocynaceae) en la Argentina

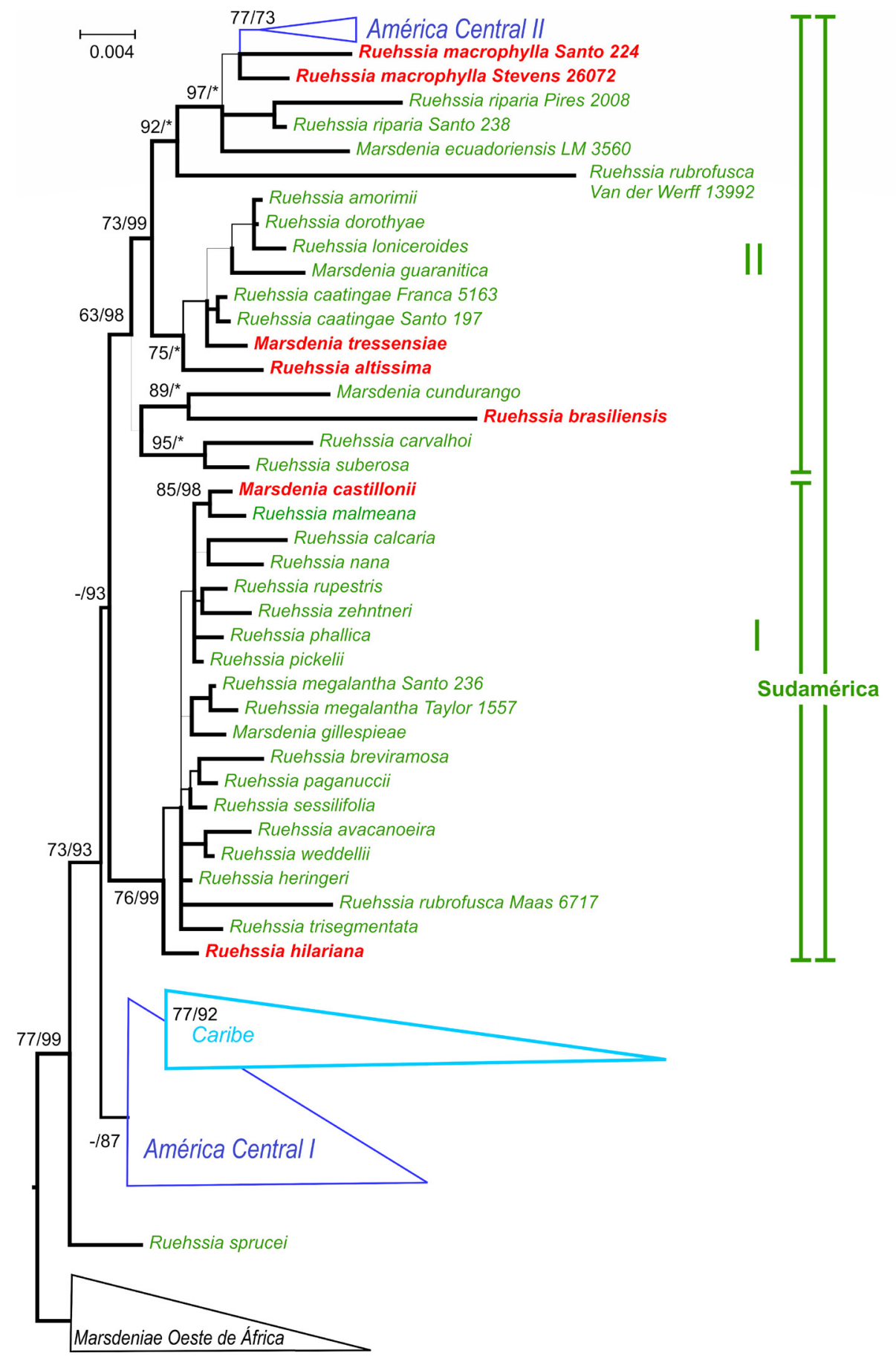

Fig. 1. Árbol de consenso de 50\% de mayoría de 63 accesiones de Marsdenieae americanas y cuatro grupos externos, basado en cinco marcadores de ADNcp y cuatro marcadores nucleares. Las cifras indican valores de soporte: Porcentajes ML Bootstrap / Probabilidades Bayesianas Posteriores. Los clados caribeños y centroamericanos se representan por medio de triángulos. Las especies en rojo son las que se encuentran en la Argentina. (*): PP = 100\%; (líneas gruesas): $\mathrm{PP} \geq 95 \%$; (líneas de espesor medio): $75 \% \leq \mathrm{PP}<95 \%$; (líneas delgadas): $\mathrm{PP}<75 \%$; (-): $\mathrm{PP}=<50 \%$. Figura en color en la versión en línea http://www.ojs.darwin.edu.ar/index.php/darwiniana/article/view/871/1190 
Dentro de este clado, M. castillonii Lillo ex T. Mey. se recupera como hermana de $R$. malmeana (W. Rothe) F. Esp. Santo \& Rapini (BS $=85 \%$, PP $=$ $98 \%$ ), formando una politomía con varios taxones brasileños. El segundo subclado sudamericano, moderadamente soportado ( $\mathrm{BS}=63 \%, \mathrm{PP}=98 \%$ ), contiene a $R$. brasiliensis (Decne.) F. Esp. Santo $\&$ Rapini, que forma una rama muy larga debido a varios insertos únicos en el espaciador trnT-trnL y el intrón rps 16, y a secuencias fuertemente desviadas para el espaciador trnH-psbA e ITS. Ruehssia brasiliensis se recupera con soporte (BS $=89 \%$, PP $=100 \%$ ) como hermana de M. cundurango Rchb. f. de Ecuador. Ruehssia altissima (Jacq.) F. Esp. Santo \& Rapini se recupera como hermana de las otras especies en un subclado pequeño y bien soportado (BS $=75 \%, P P=100 \%$ ) de especies del sur de América del Sur, que contiene a $M$. tressensiae S.A. Cáceres \& Morillo. Una muestra de R. rubrofusca (E. Fourn.) F. Esp. Santo \& Rapini de Perú se recupera como hermana de las restantes especies en otro subclado bien respaldado ( $\mathrm{BS}=92 \%, \mathrm{PP}=100 \%$ ). En este subclado, las dos muestras de la ampliamente distribuida $R$. macrophylla $\mathrm{H}$. Karst. forman una tricotomía no resuelta con un pequeño grupo de especies centroamericanas ( $M$. edulis Watson, $M$. engleriana W. Rothe y M. zimapanica Hemsl.).

\section{DISCUSIÓN}

Las seis especies argentinas reconocidas aquí se extienden por el clado sudamericano, con la ampliamente distribuida $R$. hilariana ocupando una posición (no soportada) como hermana del primer subclado sudamericano, del cual es miembro $M$. castillonii, una especie distribuida en Argentina, Bolivia y Paraguay, pero hasta ahora no registrada en Brasil. Son miembros del segundo subclado sudamericano $M$. tressensiae, endémica de la Argentina, $R$. brasiliensis con una distribución restringida en el sur de Brasil y Paraguay hasta el nordeste de la Argentina, así como también $R$. altissima, hermana de varias especies del sur de América del Sur y R. macrophylla, del segundo linaje centroamericano, aunque ello también sin soporte.

En general, el presente estudio revela una fuerte estructura geográfica en Ruehssia, a pesar del bajo soporte para algunas ramas debido a un número relativamente alto de datos faltantes. Esto es particularmente cierto para las especies mesoamericanas, que contienen las muestras con la menor cantidad de secuencias parciales disponibles. De las especies para las cuales se pudieron analizar dos accesiones, dos se recuperaron como monofiléticas ( $R$. caatingae (Morillo) F. Esp. Santo $\&$ Rapini y $R$. megalantha (Goyder \& Morillo) F. Esp. Santo \& Rapini), una sin resolver y relacionada con especies centroamericanas (R. macrophylla). En el caso de $R$. rubrofusca, la colección de la Amazonía brasileña (Maas 6717) es miembro del subclado brasileño (I) del clado sudamericano, mientras que la colección de Perú (van der Werff 13992) se recupera como hermana del segundo subclado (II), señalando un concepto posiblemente defectuoso de esta especie que merece una mayor investigación.

La posición de la especie amazónica $R$. sprucei, como hermana de todas las especies restantes del género y de los dos linajes centroamericanos derivados, sugeriría un origen sudamericano de Ruehssia e invitan a especular sobre un posible evento de dispersión desde África occidental hasta el norte de América del Sur que daría origen al linaje, un patrón que ha sido observado antes en muchos taxones (Renner, 2004). Además de $R$. sprucei, habrían evolucionado dos linajes separados, uno en América del Sur y otro en América Central, con un linaje caribeño que habría surgido después de una dispersión desde América Central. Más tarde, otro linaje centroamericano se habría establecido desde América del Sur, de modo que (al menos) dos linajes independientes evocarían la extraordinaria diversidad del género (49 especies) en América Central (TROPICOS: https://www.tropicos. org/, consultado el 30 de abril de 2020).

\section{TRATAMIENTO TAXONÓMICO}

Ruehssia H. Karst., Verh. Vereins. Beförd. Gartenbaues Königl. Preuss. Staaten 19: 304, tab. 1. 1849. ESPECIE TIPO: $R$. macrophylla (Humb. \& Bonpl. ex Schult.) H. Karst.

Sinonimia. Véase Espirito Santo et al. (2019).

Arbustos volubles o erectos con látex blanco; tallos suberosos, glabros o con tricomas, usualmente con coléteres en nudos y axilas foliares. 
Hojas opuestas, dísticas o decusadas, láminas ovadas, elípticas, obovadas, orbiculares, lanceoladas, lineares, raramente filiformes, base cuneada, cordada, obtusa, redondeada, raramente truncada; ápice agudo, cuspidado, acuminado, emarginado o redondeado; margen entero, glabra o con tricomas; adaxialmente con hasta 14 coléteres en la base de la vena principal. Inflorescencias axilares o sub-axilares, umbeliformes, glomeruladas o racemiformes, fasciculadas o paniculadas, multifloras, sésiles a largo-pedunculadas. Flores sésiles a pediceladas; pedicelos glabros o con tricomas; cáliz con lóbulos ovados, elípticos u orbiculares, abaxialmente glabros o con tricomas, márgenes ciliados o glabros, adaxialmente con hasta 20 coléteres en la axila del cáliz; corola urceolada, campanulada, tubular, hipocraterimorfa o rotada, glabra o con tricomas, lóbulos ovados, obovados, deltoides u oblongos, recurvados a erectos, márgenes ciliados o glabros; corona con 5 lóbulos, de forma diversa, completamente fusionados a la cara dorsal de las anteras o segmentadas con la parte superior libre, ocasionalmente excediendo la cabeza estilar; ginostegio inserto o exerto, sésil o estipitado; cabeza estilar ovoide, globosa, cónica o rostrada, bilobada o entera; anteras con apéndice membranoso apical usualmente oblongo, ovado a suborbicular, hialino; retináculo ovoide, oblongo, lanceolado o linear, ápice obtuso, redondeado o agudo, curvado o recto; caudículas horizontales o ascendientes, distalmente plicadas o no; polinias erectas, oblongas, obovoides, elípticas, raramente reniformes, unidas a las caudículas por su base. Folículos simples, raramente dobles, fusiformes, elipsoides, ovoides $\mathrm{u}$ oblongoides, glabros o con tricomas; semillas comosas, con margen endentado y superficie lisa.

Género neotropical constituido por aproximadamente 110 especies (Espirito Santo et al., 2019); en la Argentina, reconocemos seis especies en regiones subtropicales áridas $\mathrm{y}$ húmedas del norte del país (Fig. 2).

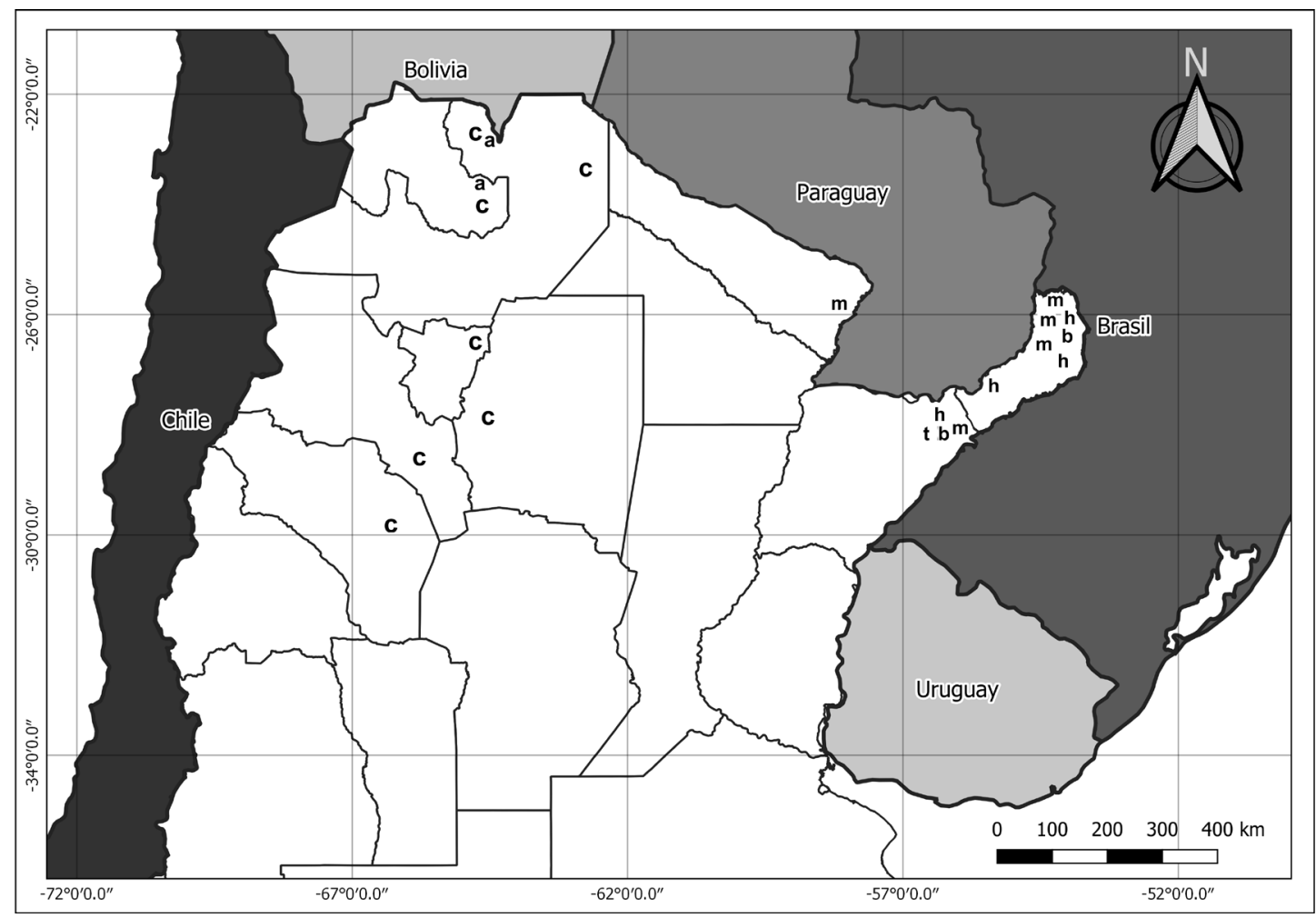

Fig. 2. Mapa de distribución del género Ruehssia en la Argentina: R. altissima (a), R. brasiliensis (b), R. castillonii (c), R. hilariana (h), R. macrophylla (m), R. tressensiae (t). 


\section{Clave para identificar las especies de Ruehssia en la Argentina}

1. Corola campanulada, garganta abierta dejando ver anteras y retináculos

1. Corola urceolada, garganta estrecha dejando ver apenas la cabeza estilar 3

2(1). Inflorescencias extendidas, corola blanca, lóbulos pubescentes con base barbada (Misiones y Corrientes)

R. brasiliensis

2. Inflorescencias congestas, corola morada a marrón-vinosa, lóbulos glabros (centro norte y noroeste argentino) ......

R. castillonii

3(1). Base de los lóbulos de la corola adaxialmente barbada

3. Base de los lóbulos de la corola glabra, con bordes ciliados, pero no barbada adaxialmente

4(3). Corola blanca, a veces con garganta lilácea, lóbulos obovados, de 5-6 mm. Frutos glabros (Corrientes) ..... R. tressensiae 4. Corola verde-vinácea, lóbulos anchamente ovados, suborbiculares o anchamente oblongos, hasta de 3,7 mm. Frutos cubierto de pelos cortos (noroeste argentino)

R. altissima

5(3). Lóbulos de la corola vináceos, de 5,1-7 mm. Frutos con más de $5 \mathrm{~cm}$ de diám. y más de 500 semillas

R. macrophylla

5. Lóbulos de la corola verdes, amarillentos, o rojizos, de hasta $4,1 \mathrm{~mm}$. Frutos con menos de $5 \mathrm{~cm}$ de diám. y menos de 400 semillas

R. hilariana

Ruehssia altissima (Jacq.) F. Esp. Santo \& Rapini, Kew Bull. 74-30:10. 2019. $\equiv$ Asclepias altissima Jacq., Enum. Syst. Pl.: 17. 1760. TIPO: Jacquin (1763: 84, tab. 57; neotipo seleccionado en Espírito Santo et al., Kew Bull. 74-30: 10. 2019). Fig. 3.

Referencias. Sinonimia, descripción e iconografía: Espirito Santo et al. (2019).

Distribución y hábitat. Especie ampliamente distribuida en Sudamérica, desde Colombia hasta el noroeste de la Argentina (Fontella-Pereira et al., 2004; Espirito Santo et al., 2019), donde crece en áreas selváticas de las provincias de Salta y Jujuy.

Fenología. En la Argentina fue recolectada en flor en los meses de octubre y febrero.

\section{Material examinado}

ARGENTINA. Jujuy. Depto. Ledesma, 13-X-1927 (fl), Venturi 5367 (LIL). Salta. Depto. Orán, Campamento río Pescado, 28-II-1943 (fl), Meyer 5012 (LIL).

Ruehssia brasiliensis (Decne.) F. Esp. Santo \& Rapini, Kew Bull. 74-30: 17. 2019. 三 Marsdenia brasiliensis Decne. en Candolle, Prodr. 8: 617. 1844. TIPO: Brasil. Mato Grosso, Serra de Cuiabá, M. Silva Manso 30 (lectotipo G00137122!, designado por Espírito Santo et al., Kew Bull. 74-30: 17. 2019). Figs. 4 y 5.
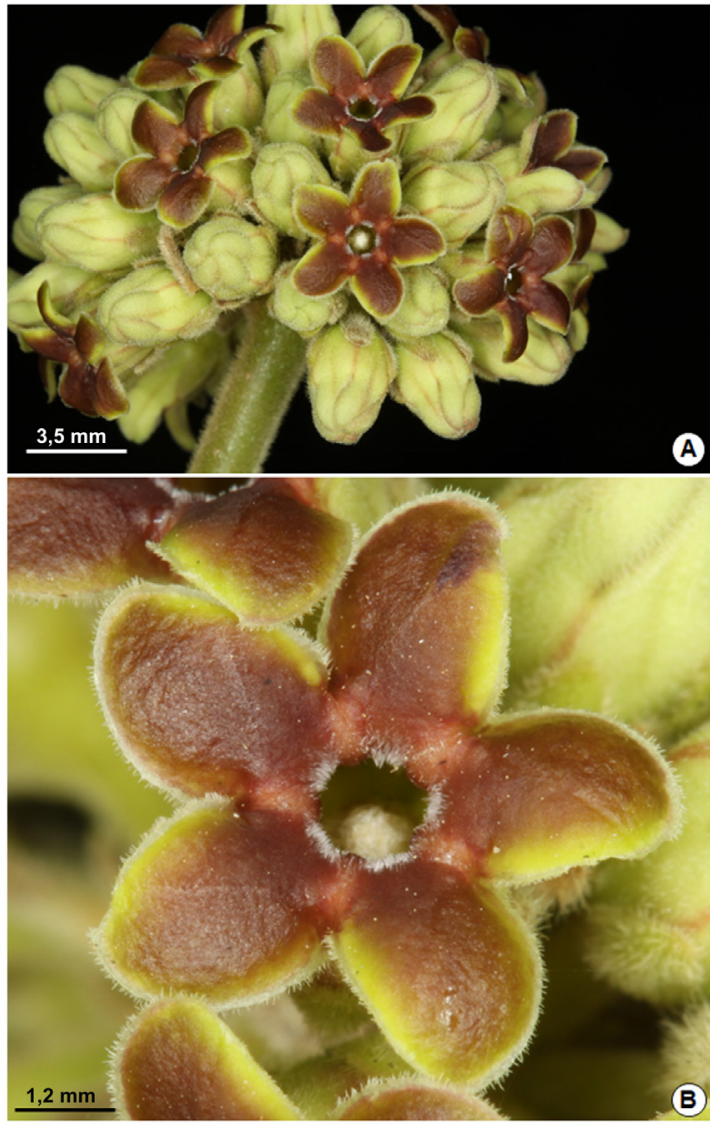

Fig. 3. Ruehssia altissima. A, inflorescencia. B, detalle de la flor, vista de cima. Fotos: Christian Zanotti. Figura en color en la versión en línea http://www.ojs.darwin. edu.ar/index.php/darwiniana/article/view/871/1190 


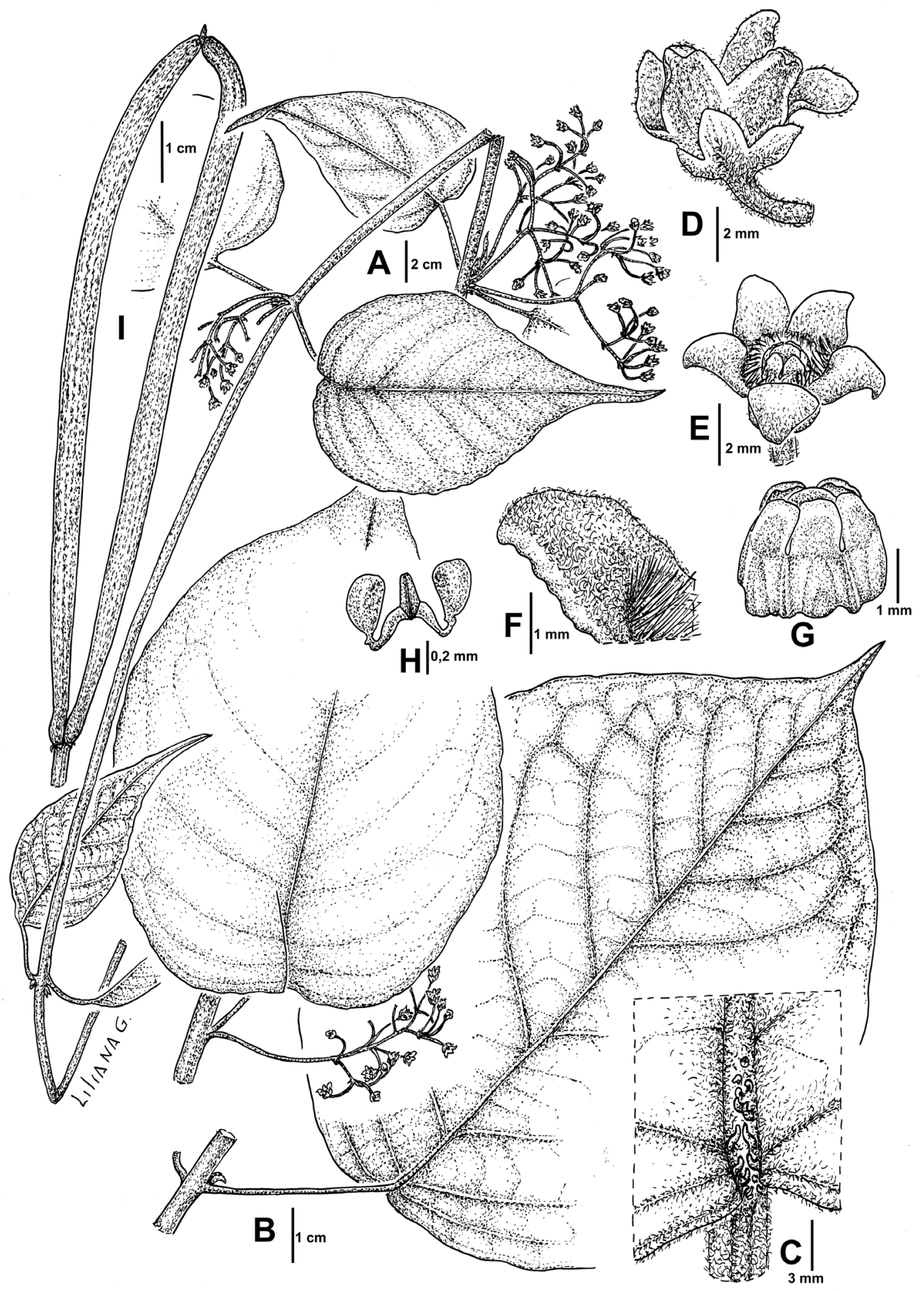

Fig. 4. Ruehssia brasiliensis. A, rama florífera. B, detalle de hoja y nervaduras. C, coléteres foliares. D, flor mostrando el cáliz. E, flor mostrando ápice del ginostegio. F, lóbulo de la corola. G, ginostegio. H, polinario. I, folículo geminado. Ilustrado por Liliana Gómez de Keller \& Erbetta 16364 (CTES). 


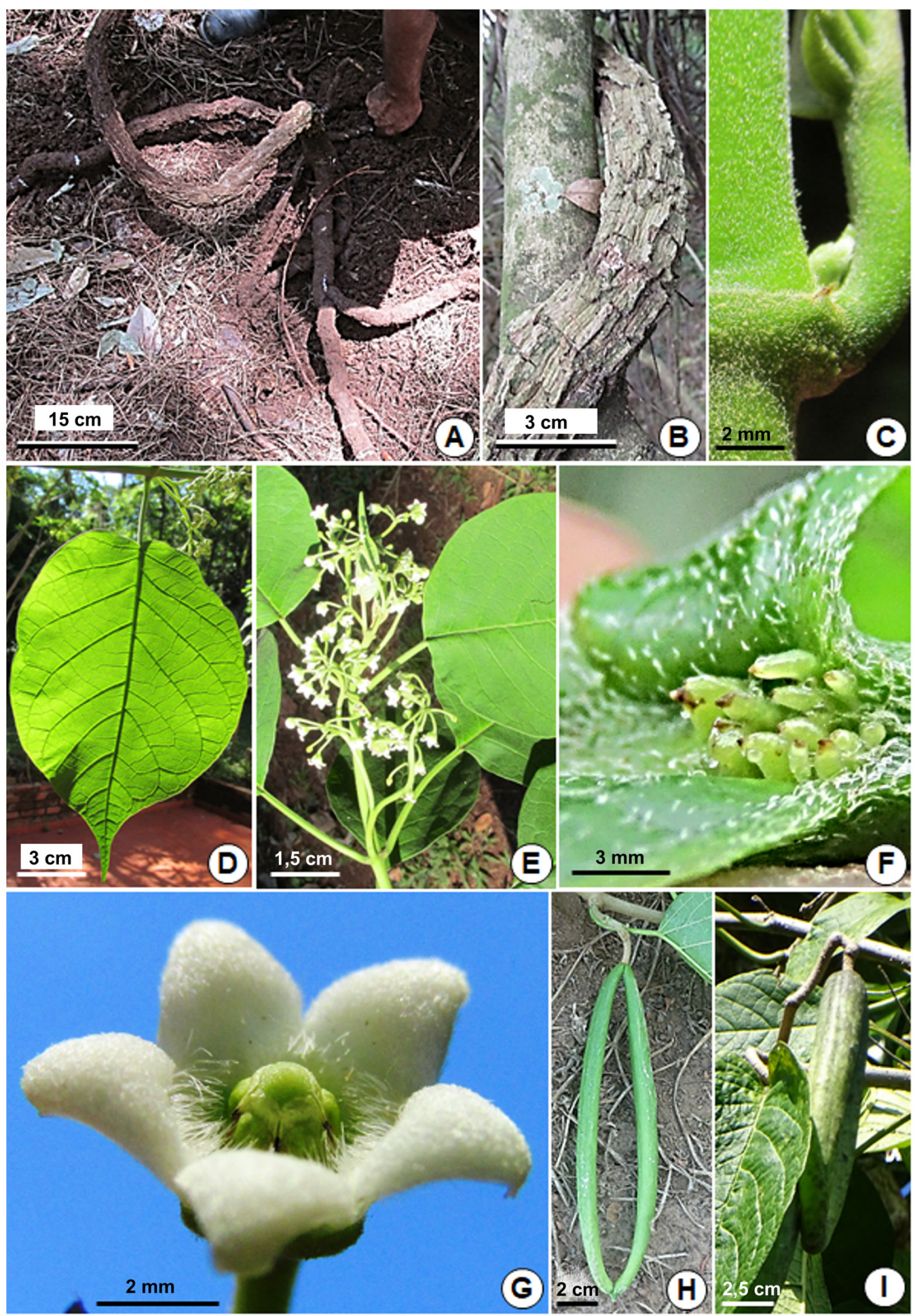

Fig. 5. Ruehssia brasiliensis. A, raíces carnosas. B, tallo. C, coléteres axilares y subaxilares. D, hoja. E, rama florífera. $\mathbf{F}$, coléteres de la hoja. G, flor. H, folículos geminados. I, folículo simple. Fotos: Héctor Keller. Figura en color en la versión en línea http://www.ojs.darwin.edu.ar/index.php/darwiniana/article/view/871/1190 
Referencias. Sinonimia y descripción: Espirito Santo et al. (2019).

Distribución y hábitat. En la Argentina, crece en el norte de Corrientes (Depto. Ituzaingó) y en Misiones. Si bien en esta última provincia sólo se ha recolectado una muestra en el Depto. Guaraní, se han observado poblaciones en los Deptos. Candelaria, Cainguás, Montecarlo, Eldorado, San Pedro e Iguazú. Crece preferentemente en selva primaria sobre suelos lateríticos, pero también ingresa en forestaciones próximas a áreas selváticas. La especie está muy poco representada en herbarios, fuera de la Argentina sólo existen dos ejemplares recolectados después del tipo. Ello podría sugerir que se trata de una especie rara, sin embargo, es posible que sea poco recolectada ya que frecuentemente florece en el dosel de la selva, a unos 15 o $20 \mathrm{~m}$ de altura.

Observaciones. Se ha observado en los ejemplares de la Argentina que la especie presenta raíces tuberosas largas de hasta $3 \mathrm{~cm}$ de diám. (Fig. 5A). Los folículos son fusiformes, rectos o curvados (Fig. 5H-I), 12-14 × 1,5-2,5 cm; cuando geminados soldados en el ápice, con pericarpio liso, glabro, verde variegado de blanco antes de la dehiscencia. Semillas no vistas.

Fenología y observaciones ecológicas. Florece desde octubre a diciembre y fructifica desde enero a marzo. Se han observado diversos visitantes florales: los coleópteros Chauliognathus flavipes (Cantharidae) y una especie no identificada de Brentiidae, los hemípteros Holymenia clavigera (Coreidae), Jadera sp. (Rhopalidae); y los lepidópteros Astraptes fulgerator (Pyriginae), Urbanus teleus (Pyriginae) y Macrorcneme sp. (Arctiidae), además de varias especies de dípteros que no se han podido determinar.

\section{Material examinado}

ARGENTINA. Corrientes. Depto. Ituzaingó, Establecimiento Santo Domingo, mogote A, $27^{\circ} 40^{\prime} 18^{\prime \prime} \mathrm{S}-56^{\circ} 10^{\prime} 48^{\prime \prime} \mathrm{O}, 4-X I I-2012$ (fl), Keller et al. 11203 (CTES). Ibídem. 27 40' 39' S - 56 10' 57' O, 8-II-2013 (fr), Keller et

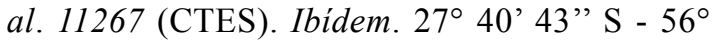

10' 57' O, 27-IX-2014 (fl), Keller \& Morillo 12294 (CTES). Ibídem. 18-XI-2014 (fl), Keller \& Franco 12402 (CTES). Misiones. Depto. Guaraní, 2639' 3" S - 54 13'39” O, 10-XI2014 (fl), Keller \& Erbetta 16364 (CTES).

Ruehssia castillonii (Lillo ex T. Mey.) H. A. Keller \& Liede, comb. nov. $\equiv$ Marsdenia castillonii Lillo ex T. Mey. en H. Descole, Gen. Sp. Pl. Argent. 2: 248, tab. 116b. 1944. TIPO: Argentina, Tucumán, Depto. Trancas, Vipos, 2-I1927. R. Schreiter s.n. (holotipo LIL 001158!). Fig. 6.

Marsdenia beckii Morillo, Anales Jard. Bot. Madrid 51(1): 55. 1993. TIPO: Bolivia, Depto. Beni, Ballivain, Espíritu en la zona de influencia del río Yacuma, Tajibal, al SE de Lucumos, 18-X-1980, S. G. Beck \& M. Liberman 5166 (holotipo LPB 0000467!; isotipos MO 274857!, MO 2815578!, NY 01163568 !, VEN no visto).

Marsdenia boliviana Morillo, Anales Jard. Bot. Madrid 51(1): 58. 1993. TIPO: Bolivia, Tarija, Gran Chaco, O'Connor, 3-4 km W de Pto. Margarita, subiendo el Río Pilcomayo, 24-X-1983, S. G. Beck 9742 (holotipo LPB 0000468 !; isotipos RB, VEN no vistos).

Referencias. Descripciones e iconografía en Meyer (1944) y Morillo (1993).

Distribución y hábitat. Se distribuye en Bolivia, Paraguay Occidental, centro y noroeste de la Argentina, en regiones subtropicales áridas y húmedas.

Observaciones. La especie adquiere hábito erecto con ramas flexuosas o se comporta como voluble. Los folículos, que constituyen un recurso alimenticio para etnias chaqueñas (Fig. 6B-C), son solitarios, fusiformes, con ápice aguzado, 12-17,2 × 1,5-2,3 cm. Placenta de 12,5-12,9 $\times 0,9-1,1 \mathrm{~cm}$ con numerosas alas membranáceas longitudinales. Semillas 140-150, de 8-11 × 4-7 mm. Penacho de 4-6 cm.

Fenología. Florece de septiembre a diciembre, recolectada en fruto en junio. 


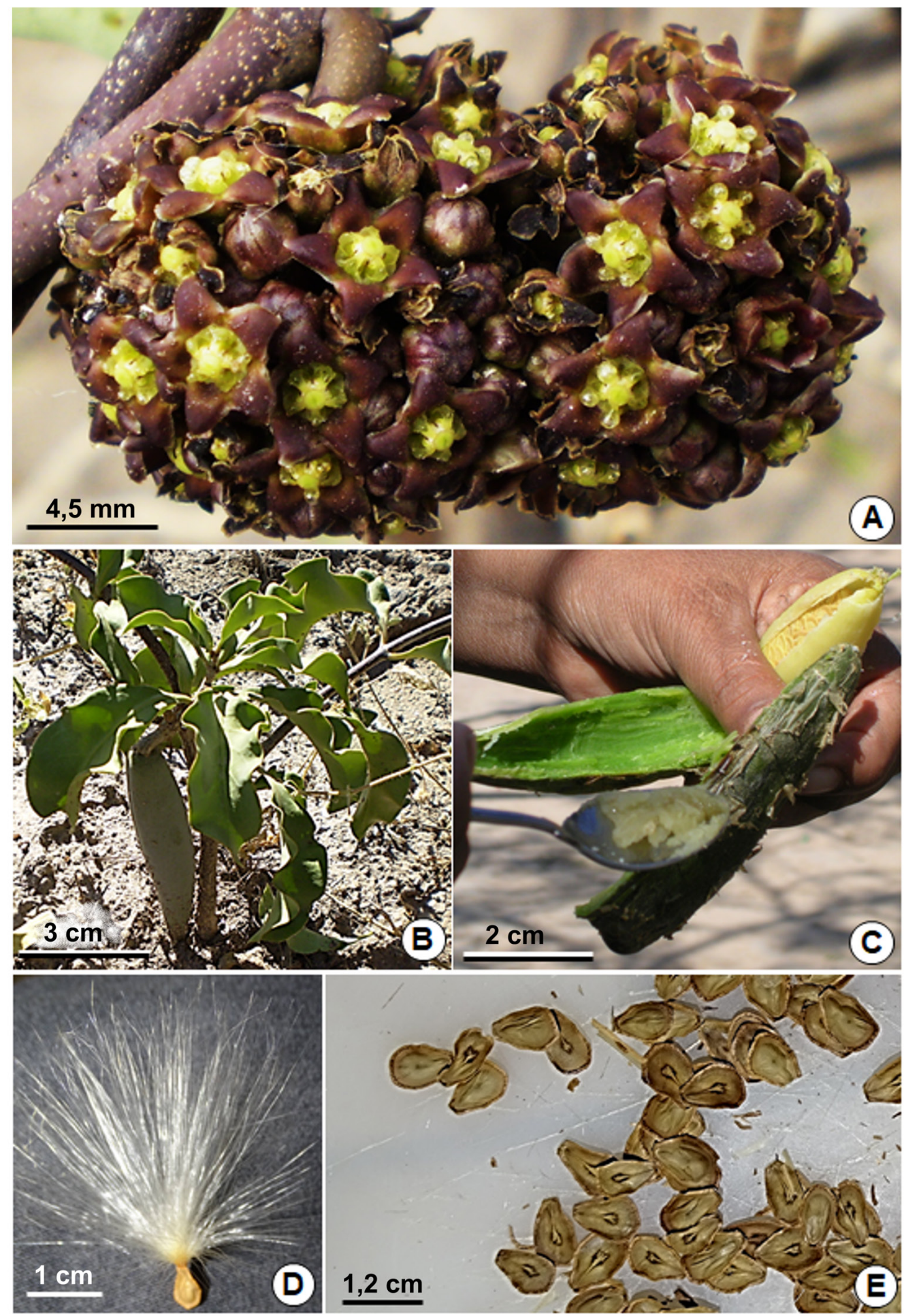

Fig. 6. Ruehssia castillonii. A, inflorescencias. B, planta con fruto. C, consumo de frutos. D, semilla con penacho. E, semillas. Fotos A-B: Alejandro Quiroga; C: María Eugenia Suarez; D-E: Héctor Keller. Figura en color en la versión en línea http://www.ojs.darwin.edu.ar/index.php/darwiniana/article/view/871/1190 


\section{Material examinado}

ARGENTINA. Catamarca. Depto. Capital, alrededores de Catamarca, 15-X-1908 (fl) Castillon 280 (LIL). Jujuy. Depto. San Pedro, San Pedro de Jujuy, 5-XI-1925 (fl) Schreiter 5197 (LIL). La Rioja. Depto. Gral. M. Belgrano, Olta, 12-VI-1998 (fr), Lutz 461 (CTES). Salta. Depto. Rivadavia, Coronel Juan Solá (Morillo), 23 29' S - 62 53' O, 19-XI-2005 (fl), Suarez 62 (CTES), Depto. Orán, Orán a Río Bermejo, X-1940 (fl), Schreiter 11386 (LIL). Santiago del Estero. Depto. Choya, Cerro Ichagón, entre $28^{\circ} 16^{\prime} 20^{\prime \prime}$ S - 64 45' 46" O y $28^{\circ} 16^{\prime} 11^{\prime \prime} \mathrm{S}-64^{\circ} 45^{\prime} 47^{\prime \prime}$ O, 4-XII-2014 (fl), Cantero et al. 6753 (CORD). Tucumán. Depto. Burruyacú, barrancas río Salí, 6-XI-1921 (fl) Venturi 1468 (LIL).

Ruehssia hilariana (E. Fourn.) F. Esp. Santo \& Rapini, Kew Bull. 74-30: 30. 2019. 三 Marsdenia hilariana E. Fourn. en Martius \& Eichler, Fl. Bras. 6 (4): 322. 1885. TIPO: Brasil, Rio de Janeiro, A. St. Hilaire s.n. cat. A2. $\mathrm{N}^{\circ} 123$ (holotipo P 00645950!). Fig. 7 y 8 .

Referencias. Sinonimia y descripción en Espirito Santo et al. (2019).

Distribución y hábitat. En la Argentina se halla en el norte de la provincia de Corrientes, donde crece en el interior y borde de la selva marginal, a la vera de cursos de agua y vertientes selváticas. En Misiones, además ha sido hallada en bordes de selvas y capueras de altura, y en borde de bañados, incluyendo la zona más alta de la provincia, a más de $800 \mathrm{~m}$ s.m.

Observaciones. Presenta tallos de hasta $10 \mathrm{~m}$ de altura y $3 \mathrm{~cm}$ de diám., con corteza suberosa agrietada. Las raíces de los ejemplares estudiados son fibrosas, a diferencia de especímenes de Brasil que presentan raíces carnosas (Pessoa et al., 2011). En los ejemplares hallados en Misiones y Corrientes, las flores son verdes con garganta amarillenta luego de la antesis, posteriormente se tornan rojizas y liberan un intenso aroma a durazno. El folículo es verde-vivo, lustroso y glabro, de 14$15 \times 4,2-4,8 \mathrm{~cm}$, placenta de $11-12 \times 1-1,1 \mathrm{~cm}$ con costillas laminares membranáceas, en un folículo se han contabilizado 332 semillas de 7-10 × 4-6 mm; penacho de 2-6 cm.

Fenología y observaciones ecológicas. Florece de octubre a diciembre, fructifica de enero a febrero. Sus hojas son consumidas por ejemplares adultos de un escarabajo del género Dotyphora (Chrysomelidae). Para evitar el flujo de látex, este coleóptero previamente drena la hoja cortando las venas principales, las que son promínulas en el hipofilo.

\section{Material examinado}

ARGENTINA. Corrientes. Depto. Ituzaingó, Establecimiento Santo Domingo, mogote A, $27^{\circ}$ 40 ' 39" S - 56 $16^{\circ}$ '56" O, 8-II-2013 (fr), Keller et al. 11266 (CTES). Ibídem. 27 40' 43' S - 56 10' 57" O, 18-XI-2014 (fl), Keller \& Franco 12403 (CTES). Misiones. Depto. Candelaria, Loreto, $27^{\circ}$ 20' 4" S - 55 32' 45" O, 5-XI-2014 (fl), Keller \& Ramirez 12356 (CTES). Depto. Gral. Manuel Belgrano, Ruta Prov. 17, Campiñas de América, cementerio, 21-X-2006 (fl), Keller 3700 (CTES). Ibídem. ca. de Dos Hermanas, $26^{\circ} 15$ ' 36" S - 53 43' 11" O, 27-XII-2013 (fl), Keller \& Hildt 11977 (CTES). Depto. Guaraní. Predio Guaraní, 26 54'$59^{\prime} \mathrm{S}$ y $54^{\circ} 12^{\prime}-18^{\prime} \mathrm{O}$, Camino a arroyo Paraíso, 26-XII-2000 (fl), Keller 494 (CTES).

Ruehssia macrophylla (Humb. \& Bonpl. ex Schult.) H. Karst., Verh. Vereins. Beförd. Gartenbaues Königl. Preuss. Staaten 19: 305. 1849. $\equiv$ Asclepias macrophylla Humb. \& Bonpl. ex Schult., Syst. Veg. (ed. 15 bis) 6: 86. 1820. TIPO: Venezuela, "Bordones. in umbrosis", IX/X-1799, F. W. H. A. Humboldt \& A. J. A. Bonpland 361 (holotipo B W 05270-010!; isotipo P 00645953!). Fig. 9.

Referencias. Sinonimia y descripción en Espirito Santo et al. (2019).

Distribución y hábitat. Crece en el interior y borde de selva primaria y capueras en todo Misiones. En Corrientes, se han observado ejemplares adultos y renuevos en interior de parches de selva del norte provincial. Ha sido también hallada en Formosa en la región del Chaco Sub-húmedo. 


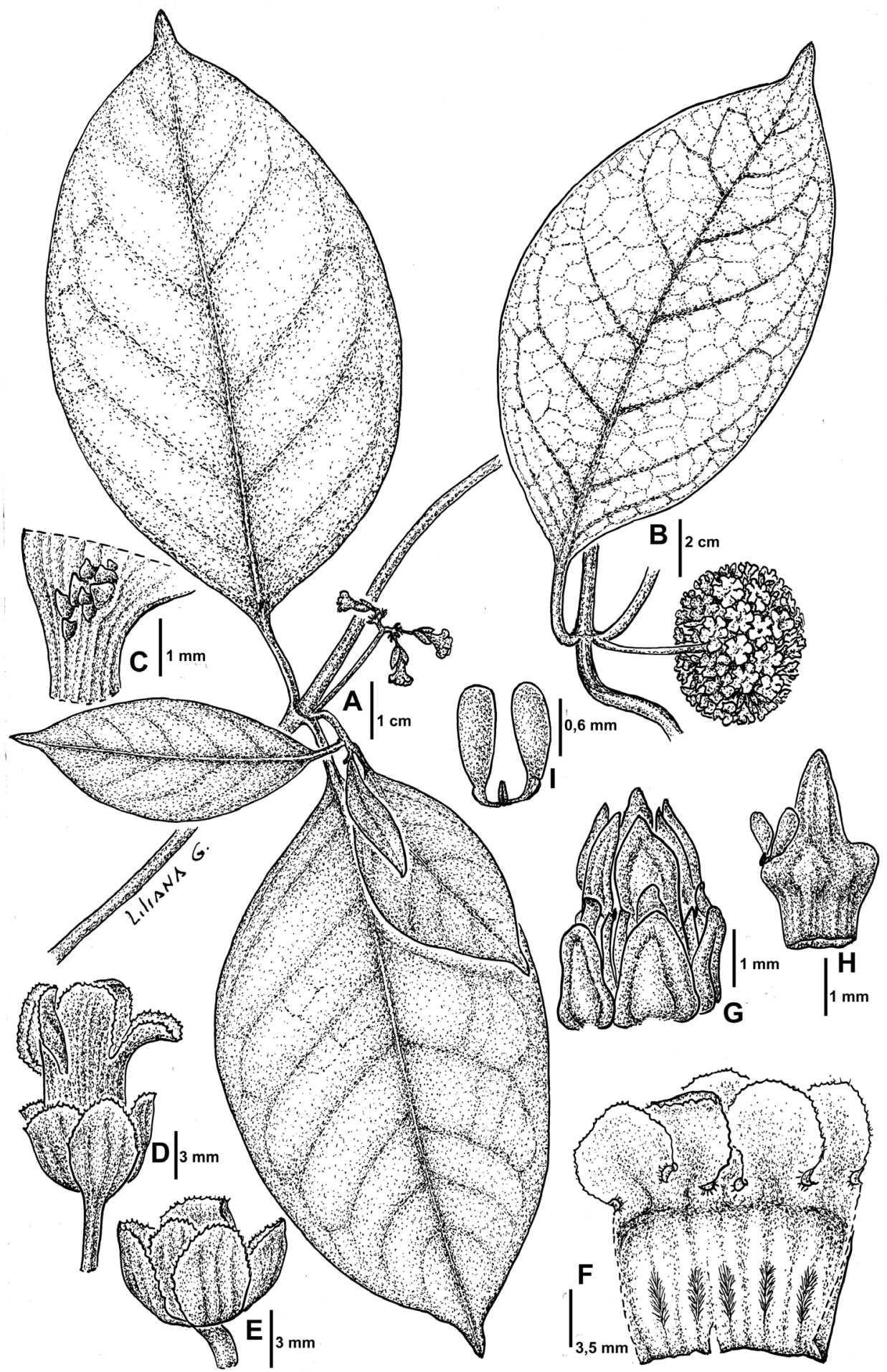

Fig. 7. Ruehssia hilariana. A, rama florífera. B, nudo con inflorescencia y hoja con detalle de venación. C, coléteres foliares. D, flor. E, cáliz. F, corola abierta. G, ginostégio. H, ginostégio desprovisto de anteras. I, polinario. Ilustrado por Liliana Gómez de Keller \& Ramírez 12356 (CTES). 

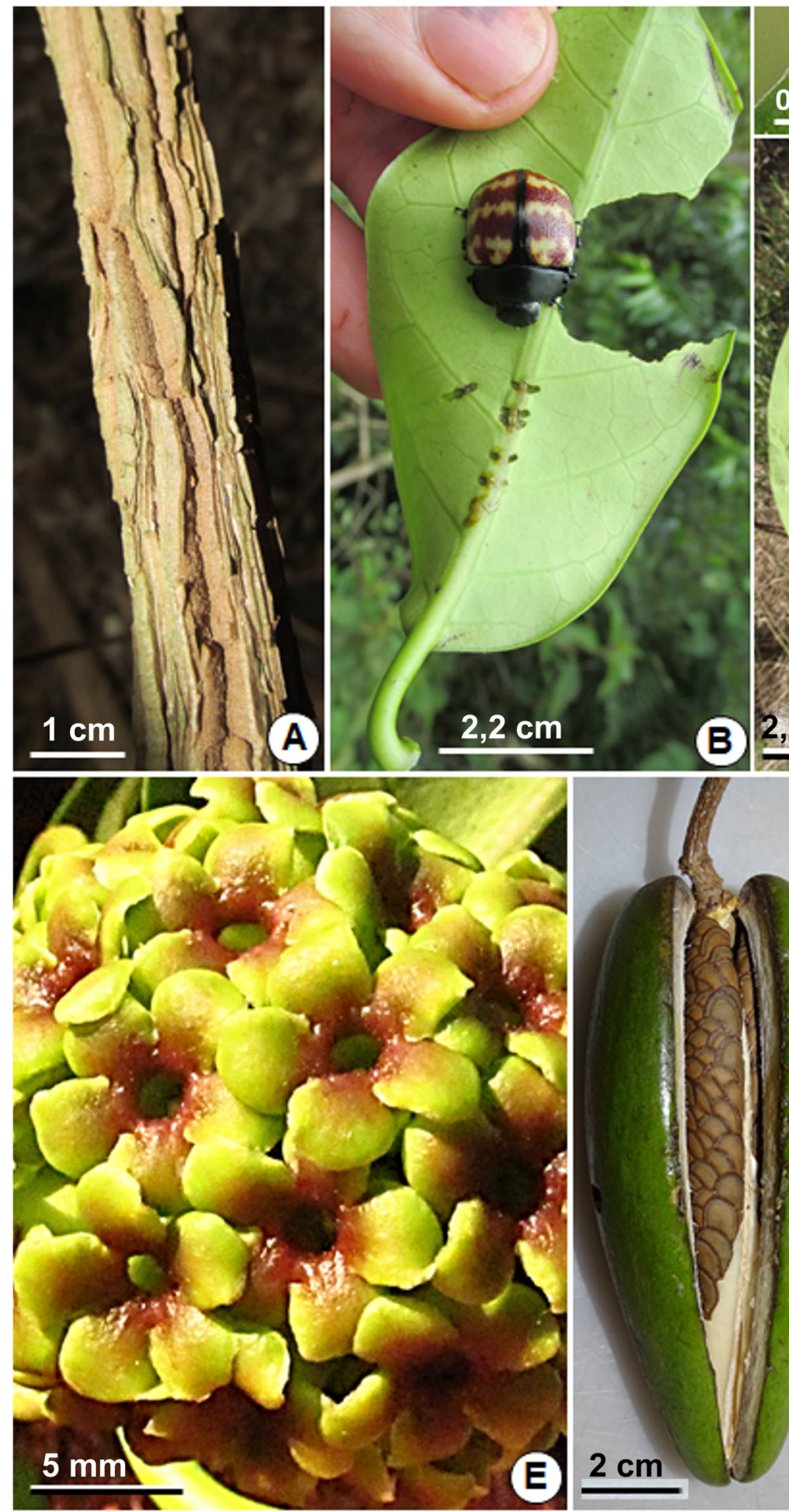

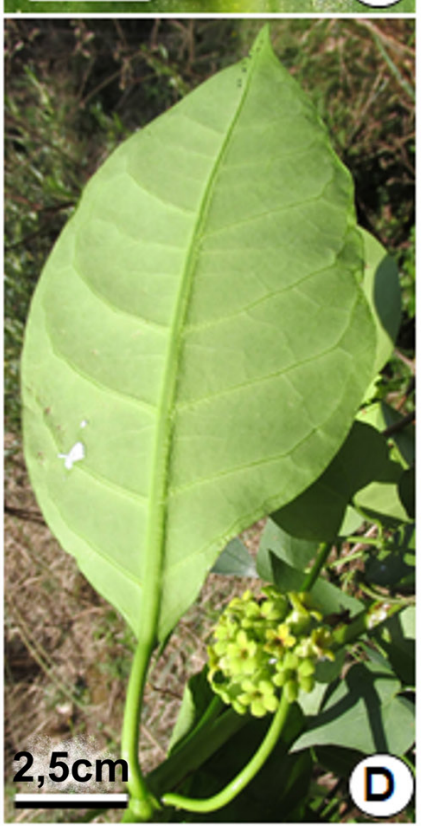

Fig. 8. Ruehssia hilariana. A, tallo. B, hoja consumida por coleóptero. C, coléteres foliares. D, rama florífera. E, flores. F, fruto abierto, mostrando las semillas. G, semillas. Fotos: Héctor Keller. Figura en color en la versión en línea http://www.ojs.darwin.edu.ar/index.php/darwiniana/article/view/871/1190 


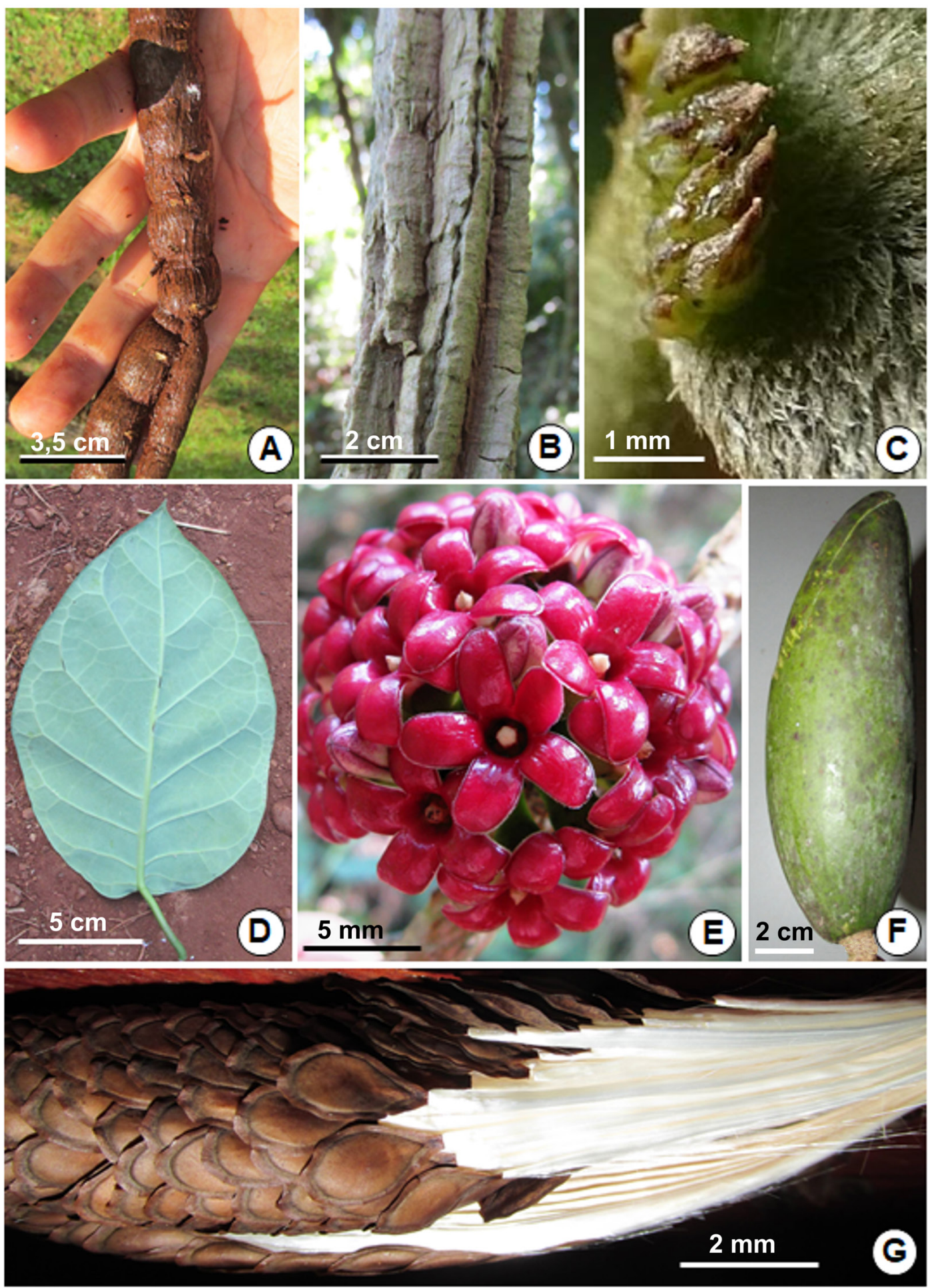

Fig. 9. Ruehssia macrophylla. A, raíces. B, tallo. C, coléteres foliares. D, hoja. E, inflorescencia. F, fruto. G, semillas con penacho. Fotos: Héctor Keller. Figura en color en la versión en línea http://www.ojs.darwin.edu.ar/index.php/ darwiniana/article/view/871/1190 
Observaciones. A los tratamientos ya efectuados previamente se puede añadir que se trata de una liana selvática latescente, con tallos de hasta 20 $\mathrm{m}$ de altura y $4 \mathrm{~cm}$ de diám. En estado vegetativo, es similar a Macropharynx peltata (Vell.) J.F. Morales, M.E. Endress \& Liede, de la que se diferencia por su corteza agrietada con domos suberosos blandos al tacto y por sus hojas grandes no peltadas. A la descripción de Fournier (1885) y de Meyer (1947) se añaden aquí datos sobre raíces, frutos y semillas.

En su sistema radicular basal, así como en los tallos en contacto con el manto orgánico del suelo selvático, se desarrollan raíces tuberosas de hasta $50 \times 5 \mathrm{~cm}$.

Los frutos se constituyen por lo general de folículos simples, fusiformes, levemente curvados, de $16,7-17,2 \times 5,4-5,5 \mathrm{~cm}$. Contienen de 512 a 596 semillas obovadas, marginado-membranáceas, de 1,5-1,6 × 0,9-1,1 cm; penacho blanco de 1,5-7 cm; embrión con cotiledones oblongo-elípticos, ca. de $6 \times 4 \mathrm{~mm}$ y radícula de $3 \mathrm{~mm}$.

Fenología y observaciones ecológicas. Florece de septiembre a diciembre, fructifica de octubre a enero. Sus hojas son también consumidas por ejemplares adultos de un escarabajo del género Dotyphora (Chrysomelidae).

\section{Material examinado}

ARGENTINA. Corrientes. Depto. Ituzaingó, 17 km NW de San Carlos, Estancia. Rincón Chico, 11-XII-1984 (fl), Tressens 3806 (CTES). Formosa. Depto. Capital, Estancia Guaycolec, C 600, Reserva Guaycolec, 5-XII-2014 (fl, fr), Dávalos 57 (CTES). Misiones. Depto. Iguazú, San Isidro Labrador, 18X-2014 (fr), Keller et al. 12335 (CTES). Depto. Montecarlo, 26 34' 30" S - 54 ${ }^{\circ} 25^{\prime} 45^{\prime \prime}$ O, 18-X2014 (fl), Keller et al. 12337 (CTES).

Ruehssia tressensiae (S.A. Cáceres \& Morillo) H.A. Keller \& Liede, comb nov. $\equiv$ Marsdenia tressensiae S. A. Cáceres \& Morillo, Bonplandia. 7: 34. 1993. TIPO: Argentina, Corrientes, Capital, Facultad de Ciencias Agrarias, cultivado a partir de una rama de1 ejemplar Cáceres 375, del río Aguapey y ruta 38, 21-X-1988, (fl), S. Cáceres 426 (holotipo CTES
0014094!; isotipos ASU 0017033!, BAA!, BAB 00000051!, C 10006772!, FCQ!, G 00177054!, GH 00076477!, HAS 32979!, K 000438810!, LIL 001160!, LPB!, MBM 162595!, MICH 1111615!, MO 04909593!, NY 00007169!, P 00645968!, SI 000796!, U 0000694!, UB!, VEN!). Fig. 10.

Referencias. Descripción ampliada e iconografía en Cáceres Moral (1993).

Distribución y hábitat. Hasta el presente es considerada endémica de la selva marginal del arroyo Aguape-i, en el norte de la provincia de Corrientes.

Observaciones. Las raíces son fibrosas, no carnosas. Las flores tienen olor a jazmín. Se han contado un total de 264 semillas en el fruto estudiado.

Fenología y observaciones ecológicas. Florece en noviembre-diciembre. Se han observado diversos visitantes florales, durante el día himenópteros de las familias Halictidae y Pompilidae y durante la noche lepidópteros de la familia Crambidae, pero no se ha podido constatar el transporte de polinias.

\section{Material examinado}

ARGENTINA. Corrientes. Depto. Ituzaingó, puente sobre arroyo Aguape-í, 27 $36^{\prime} 12$ " S $56^{\circ} 14$ ' 33' O, 22-XI-2017 (fl), Keller \& Rojas 13712 (CTES).

\section{Especies excluidas}

Ruehssia montana (Malme) F. Esp. Santo \& Rapini, Kew Bull. 74-30: 42. 2019. Marsdenia montana Malme, Kongl. Svenska Vetensk. Acad. Handl., n. s. 34(7): 93, tab. 8, fig. 51. 1900. TIPO: Regnell III 893 (lectotipo S 032285!, designado por Espírito Santo et al., Kew Bull. 74-30: 42. 2019); isolectotipos C!, NY!, S!, P, US!).

El material Keller 494 (CTES) identificado como Marsdenia montana Malme en Tressens et al. (2008) corresponde a $R$. hilariana ya que 


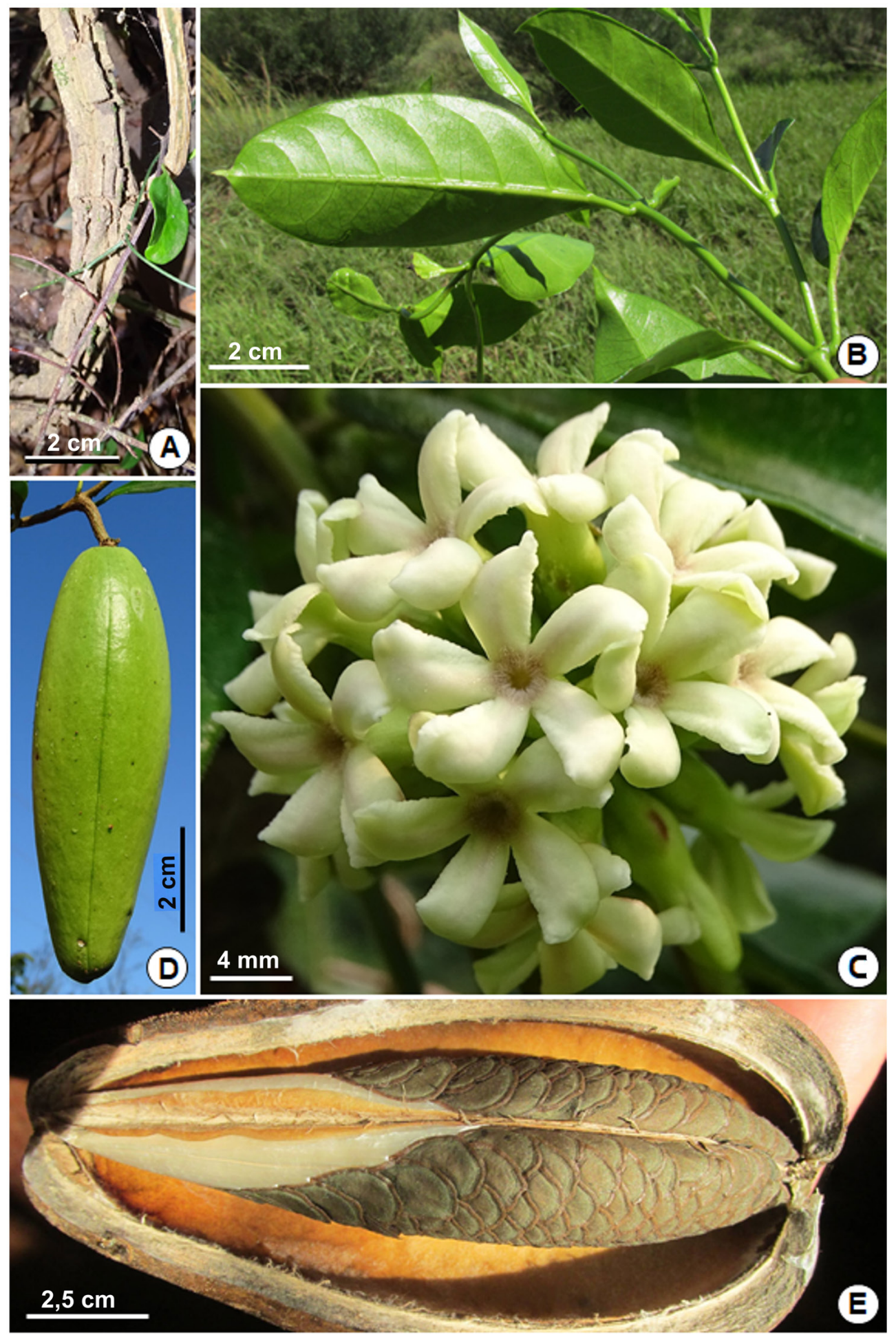

Fig. 10. Ruehssia tressensiae. A, tallo. B, rama con hojas. C, inflorescencia. D, fruto. E, fruto abierto mostrando semillas con penacho. Fotos: Héctor Keller. Figura en color en la versión en línea http://www.ojs.darwin.edu.ar/ index.php/darwiniana/article/view/871/1190 
el tubo de la corola es apenas más largo que el ginostegio. En $R$. montana el tubo de la corola triplica en longitud al ginostegio (Rothe, 1915; Fontella-Pereira et al., 2004).

Ruehssia ulei (Schltr. \& W. Rothe) F. Esp. Santo \& Rapini, Kew Bull. 74-30: 66. 2019. Marsdenia ulei Schltr. \& W.Rothe, Bot. Jahrb. Syst. 52(4): 413. 1915. TIPO: Brazil, Bahia, "Catinga bei Caldeirao", Ule 7012 (holotipo B; neotipo foto F0BN-004091!, designado por Espírito Santo et al., Kew Bull. 74-30: 66. 2019).

Sobre la base de ejemplares recolectados en Orán (Salta) y San Pedro (Jujuy), dos localidades subtropicales del noroeste argentino, Meyer (1944) incluye para la Argentina a Marsdenia ulei Schltr. \& W. Rothe y en su clave la diferencia de M. castillonii Lillo ex T. Mey. por presentar la primera especie ginostegio más alto $(2 \mathrm{~mm}$ contra $1 \mathrm{~mm}$ ) y lacinias del cáliz más largas que la segunda $(3,5 \mathrm{~mm}$ contra menos de $2 \mathrm{~mm})$. En el ejemplar de Salta, Schreiter 11386 (LIL!), se observa el epíteto "castillonii" escrito a lápiz, sobre el cual Meyer sobrescribe "ulei" con tinta. En las ilustraciones que presenta Meyer (1944), ambas especies se aprecian con caracteres muy similares entre sí, pero diferentes a la descripción ampliada y la ilustración presentada por Espírito Santo et al. (2019), quienes indican que R. ulei hasta el presente es sólo conocida por el ejemplar tipo colectado hace más de un siglo en la Catinga de Bahia, Brasil.

Al estudiar varias muestras de la Argentina de $R$. castillonii, notamos que las flores y sus estructuras presentan cierto rango de variación en tamaño, lo que también queda evidenciado en las medidas del ginostegio y las piezas del cáliz que Morillo (1993) señala para el protólogo de dos especies que hoy son sinónimos de $R$. castillonii, medidas que comprenden e incluso sobrepasan el rango empleado por Meyer (1944) para diferenciarlas. Por todo ello, concluimos que las muestras determinadas y citadas como M. ulei para la Argentina son ejemplares de Ruehssia castillonii, con estructuras florales de mayor tamaño, posiblemente por no crecer en el ambiente árido típico de la especie.

\section{AGRADECIMIENTOS}

Agradecemos el envío de fotos que ilustran esta contribución a Alejandro Quiroga (INTA-EEACatamarca) y a Eugenia Suarez (INMIBO). También a Liliana Gómez (IBONE), autora de los dibujos de $R$. brasiliensis y $R$. hilariana. SLS agradece a Tatyana Livshultz (Drexel University) por el uso de secuencias no publicadas de Anisopus efulensis, A. mannii, Marsdenia guaranitica, M. laxiflora y Ruehssia rubrofusca, y a Livia Wanntorp (KTH Royal Institute of Technology) por las secuencias de Marsdenia coulteri, M. edulis, M. ekmanii, M. mayana, M. peraffinis, y Ruehssia clausa. A los revisores y editores que han contribuido sustancialmente e la mejora del manuscrito.

\section{BIBLIOGRAFÍA}

Cáceres Moral, S. A. 1993. Dos nuevas especies de Oxypetalum y Marsdenia (Asclepiadaceae) de Argentina. Bonplandia 7: 31-38.

Darriba, D.; D. Posada; A. M. Kozlov; A. Stamatakis; B. Morel \& T. Flouri. 2020. ModelTest-NG: a new and scalable tool for the selection of DNA and protein evolutionary models. Molecular Biology and Evolution 37: 291-294.

Endress, M. E.; U. Meve, D. J. Middleton \& S. Liede-Schumann. 2018. Apocynaceae, en J. W. Kadereit \& V. Bittrich (eds.), The Families and Genera of Vascular Plants 15: 207-411. Cham: Springer.

Espírito Santo F. S.; A. Rapini; P. L. Ribeiro; S. LiedeSchumann; D. J. Goyder \& J. Fontella-Pereira. 2019. Phylogeny of the tribe Marsdenieae (Apocynaceae), reinstatement of Ruehssia and the taxonomic treatment of the genus in Brazil. Kew Bulletin 74: 1-79.

Fontella-Pereira, J.; M. C. Valente; N. M. S. Marquete \& C. L. F. Ichaso. 2004. Apocináceas-Asclepiadóideas, en A. Reis (ed.), Flora Ilustrada Catarinense, pp 224. Itajaí: Herbário Barbosa Rodrigues.

Fournier, E. 1885. Asclepiadaceae, en C. F. P. Martius \& A. G. Eichler [Urban 1887-1906] (eds.), Flora Brasiliensis 6 (4): 189-331; tabs 50-98. Monachii: Typographia Regia.

Huelsenbeck, J. P. \& F. Ronquist 2001. MRBAYES: Bayesian inference of phylogeny. Bioinformatics 17: 754-755.

Karsten, G. K. W. H. 1849. Ruehssia estebanensis, Ruehssia glauca, Ruehssia macrophylla, Ruehssia maculata, Ruehssia pubescens. Verh. Vereins. Beförd. Gartenbaues Königl. Preuss. Staaten 19: 305. 
Katoh, K. \& D. M. Standley. 2013. MAFFT multiple sequence alignment software version 7: improvements in performance and usability. Molecular Biology and Evolution 30: 772-780.

Lemoine, F.; D. Correia; V. Lefort; O. Doppelt-Azeroual; F. Mareuil; S. Cohen-Boulakia \& O. Gascuel. 2019. NGPhylogeny. fr: new generation phylogenetic services for non-specialists. Nucleic Acids Research 47: 260-265.

Liede-Schumann, S.; A. Rapini; D. J. Goyder \& M. W. Chase. 2005. Phylogenetics of the New World subtribes of Asclepiadeae (Apocynaceae-Asclepiadoideae): Metastelmatinae, Oxypetalinae and Gonolobinae. Systematic Botany 30: 184-200.

Maddison, W. P. \& D. R. Maddison. 2019. Mesquite: a modular system for evolutionary analysis. Version 3.51.

Meyer, T. 1944. Asclepiadaceae, en H. R. Descole (ed.), Genera et Species Plantarum Argentinarum 2: 1-273. Buenos Aires: Kraft.

Meyer, T. 1947. Asclepiadaceae Argentinensis novae aut criticae III. Lilloa 13: 24-29.

Miller, M. A.; W. Pfeiffer \& T. Schwartz. 2010. Creating the CIPRES Science Gateway for inference of large phylogenetic trees. In: Proceedings of the Gateway Computing Environments Workshop (GCE), 14 Nov. 2010, New Orleans, LA, pp 1-8.

Morillo, G. 1993. Nuevos taxones sudamericanos en el género Marsdenia R. Br. (Asclepiadaceae). Anales del Jardín Botánico de Madrid 51: 55-63.

Pessoa, C. R. M.; F. Riet-Correa; R. M. T. Medeiros; S. V. D. Simões \& A. Rapini. 2011. Poisoning by Marsdenia hilariana and Marsdenia megalantha (Apocynaceae) in ruminants. Toxicon 58: 610-613.

Piel, W. H.; L. Chan; M. J. Dominus; J. Ruan; R. A. Vos \& V. Tannen 2009. TreeBASE v. 2: A Database of Phylogenetic Knowledge. En: e-BioSphere 2009.

Rambaut, A.; A. J. Drummond; D. Xie; G. Baele \& M. A. Suchard. 2018. Posterior summarisation in Bayesian phylogenetics using Tracer 1.7. Systematic Biology 67: 901-904.

Rapini, A.; M. W. Chase; D. J. Goyder \& J. Griffiths. 2003. Asclepiadeae classification: evaluating the phylogenetic relationships of New World Asclepiadoideae (Apocynaceae). Taxon 52: 33-50.

Rapini, A.; C. Berg \& S. Liede-Schumann. 2007. Diversification of Asclepiadoideae (Apocynaceae) in the New World. Annals of the Missouri Botanical Garden 94: 407-422.
Renner, S. S. 2004. Plant dispersal across the tropical Atlantic by wind and sea currents. International Journal of Plant Sciences. 165(S4): S23-S33.

Rodríguez, F.; J. L. Oliver; A. Marín \& J. R. Medina. 1990. The general stochastic model of nucleotide substitution. Journal of Theoretical Biology 142: 485-501.

Ronquist, F. \& J. P. Huelsenbeck. 2003. MRBAYES 3: Bayesian phylogenetic inference under mixed models. Bioinformatics 19: $1572-1574$

Rothe, W. 1915. Über die Gattung Marsdenia R. Br. und die Stammpflanze der Condurangorinde. Botanische Jahrbücher für Systematik 52: 354-434.

Sang, T.; D. J. Crawford \& T. F. Stuessy. 1997. Chloroplast DNA phylogeny, reticulate evolution, and biogeography of Paeonia (Paeoniaceae). American Journal of Botany 84: 1120-1136.

Stamatakis, A. 2014. RAxML version 8: a tool for phylogenetic analysis and post-analysis of large phylogenies. Bioinformatics 30: 1312-1313.

Straub, S.C.K.; M. Fishbein; T. Livshultz; Z. Foster; M. Parks; K. Weitemier; R. C. Cronn, \& A. Liston. 2011. Building a model: developing genomic resources for common milkweed (Asclepias syriaca) with low coverage genome sequencing. BMC Genomics 12: 211.

Taberlet, P.; L. Gielly; G. Pautou \& J. Bouvet. 1991. Universal primers for amplification of three non-coding regions of chloroplast DNA. Plant Molecular Biology 17: 1105-1109.

Talavera, G. \& J. Castresana. 2007. Improvement of phylogenies after removing divergent and ambiguously aligned blocks from protein sequence alignments. Systematic Biology 56: 564-577.

Thiers, B. [permanentemente actualizado, consulta 2020] Index Herbariorum: a global directory of public herbaria and associated staff. New York Botanical Garden's Virtual Herbarium, http://sweetgum.nybg.org/ih

Tressens, S. G.; H. A. Keller \& V. Revilla. 2008. Las plantas vasculares de la Reserva de Uso Múltiple Guaraní, Misiones (Argentina). Boletín de la Sociedad Argentina de Botánica 43: 273-293.

Vos, R. A.; J. P. Balhoff; J. A. Caravas; M. T. Holder; H. Lapp; W. P. Maddison; P. E. Midford; A. Priyam; J. Sukumaran; X. Xia \& A. Stoltzfus. 2012. NeXML: rich, extensible, and verifiable representation of comparative data and metadata. Systematic Biology 61: 675-689. 
H. A. KELLER ET AL. Ruehssia (Apocynaceae) en la Argentina

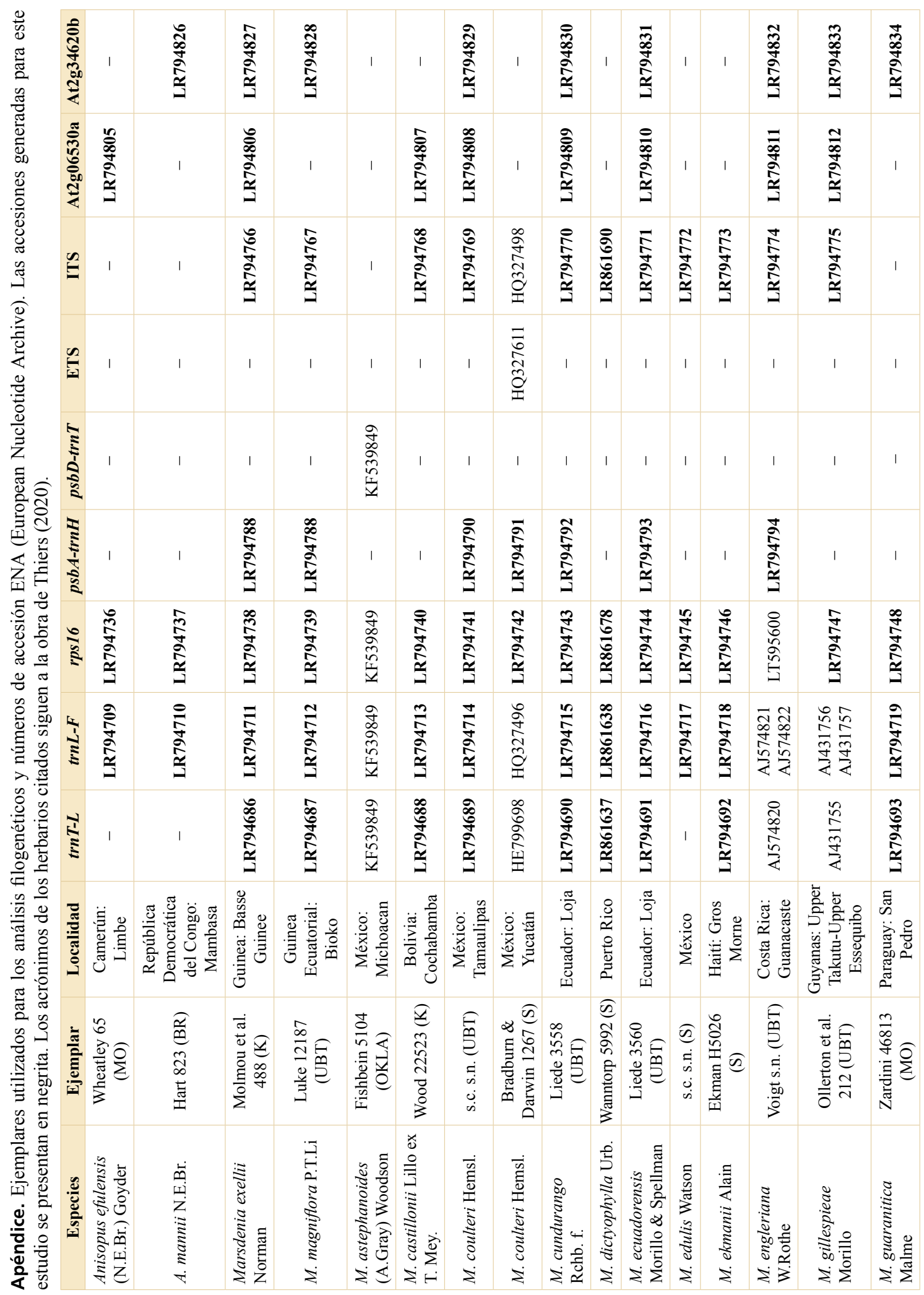




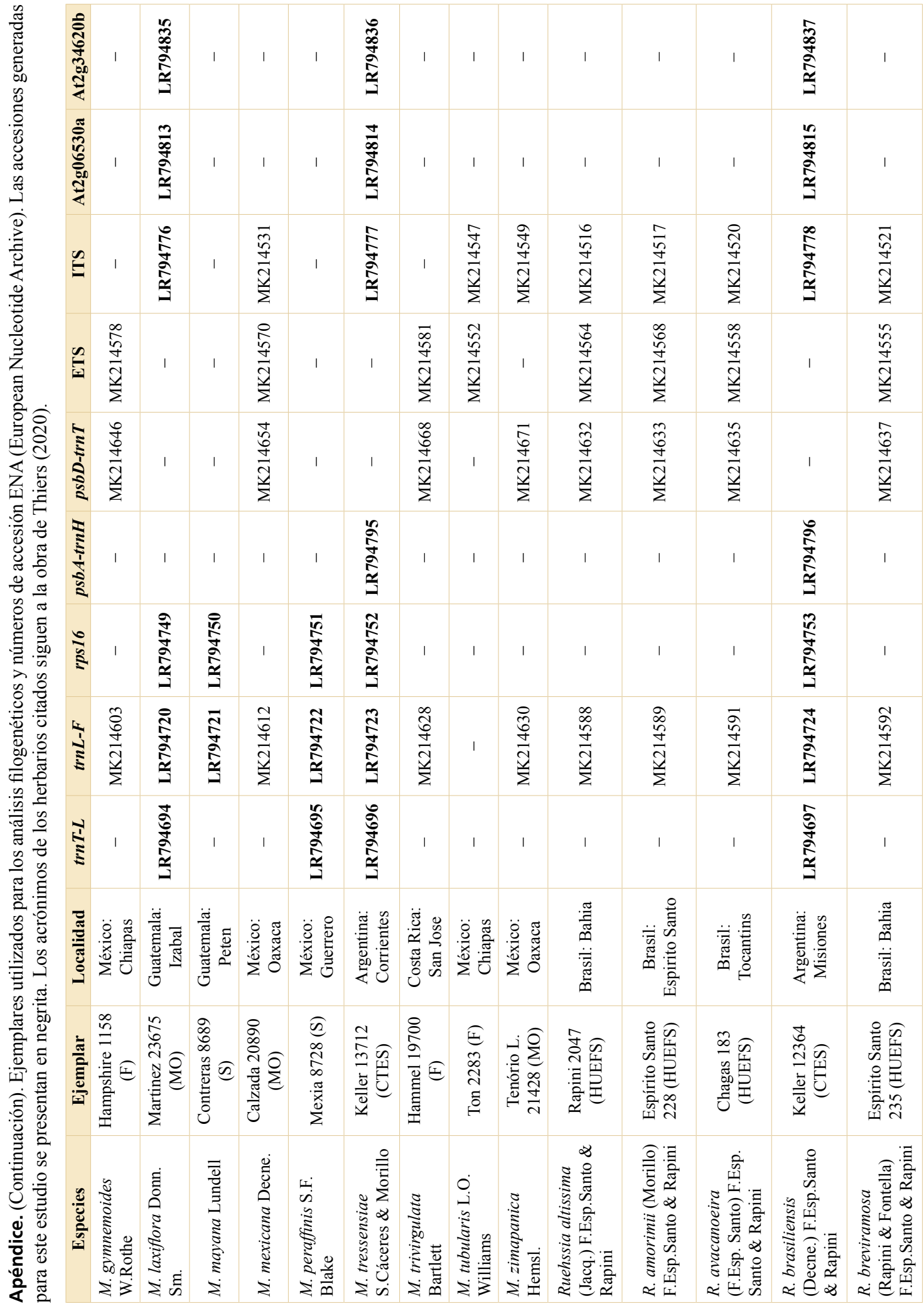




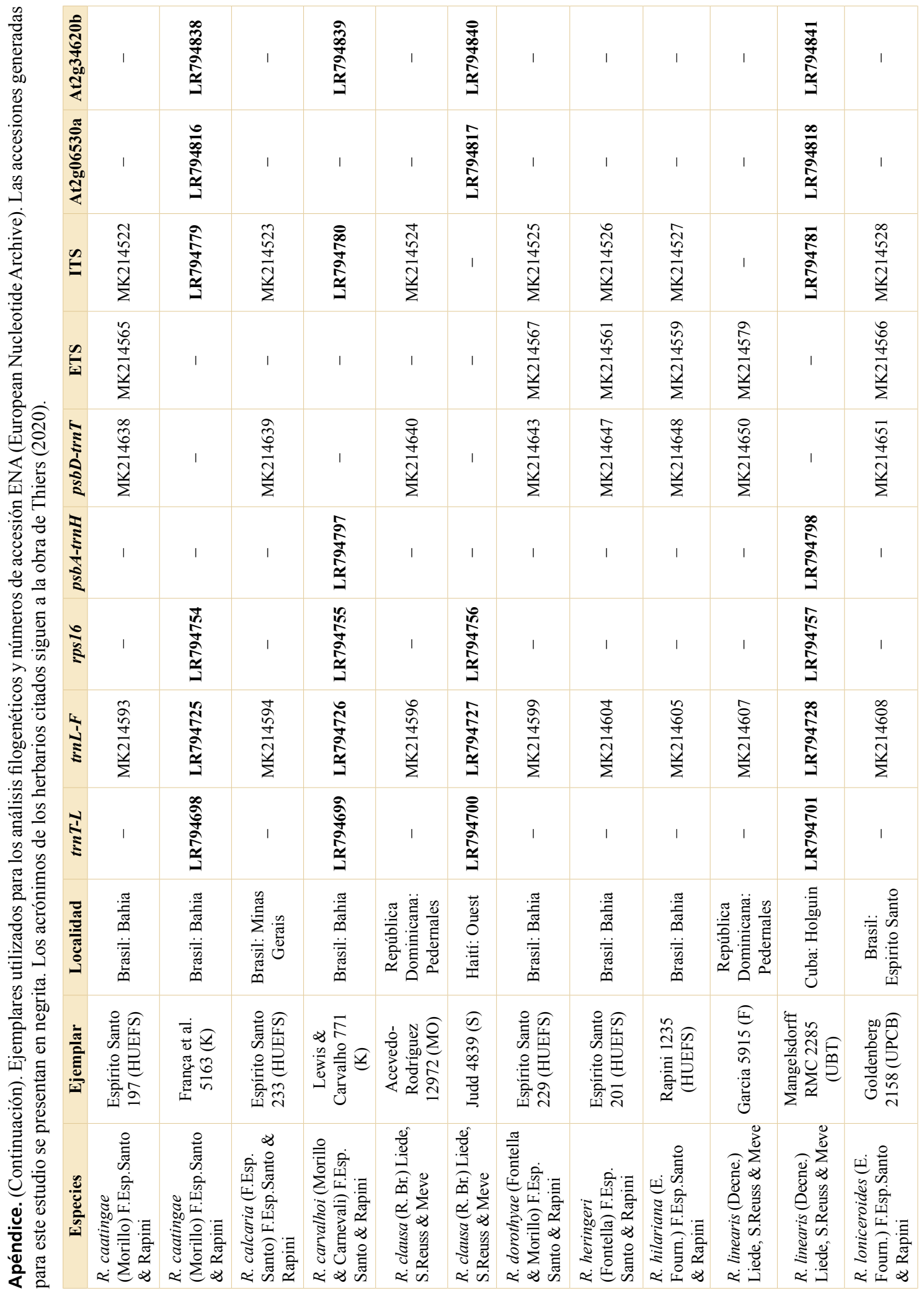




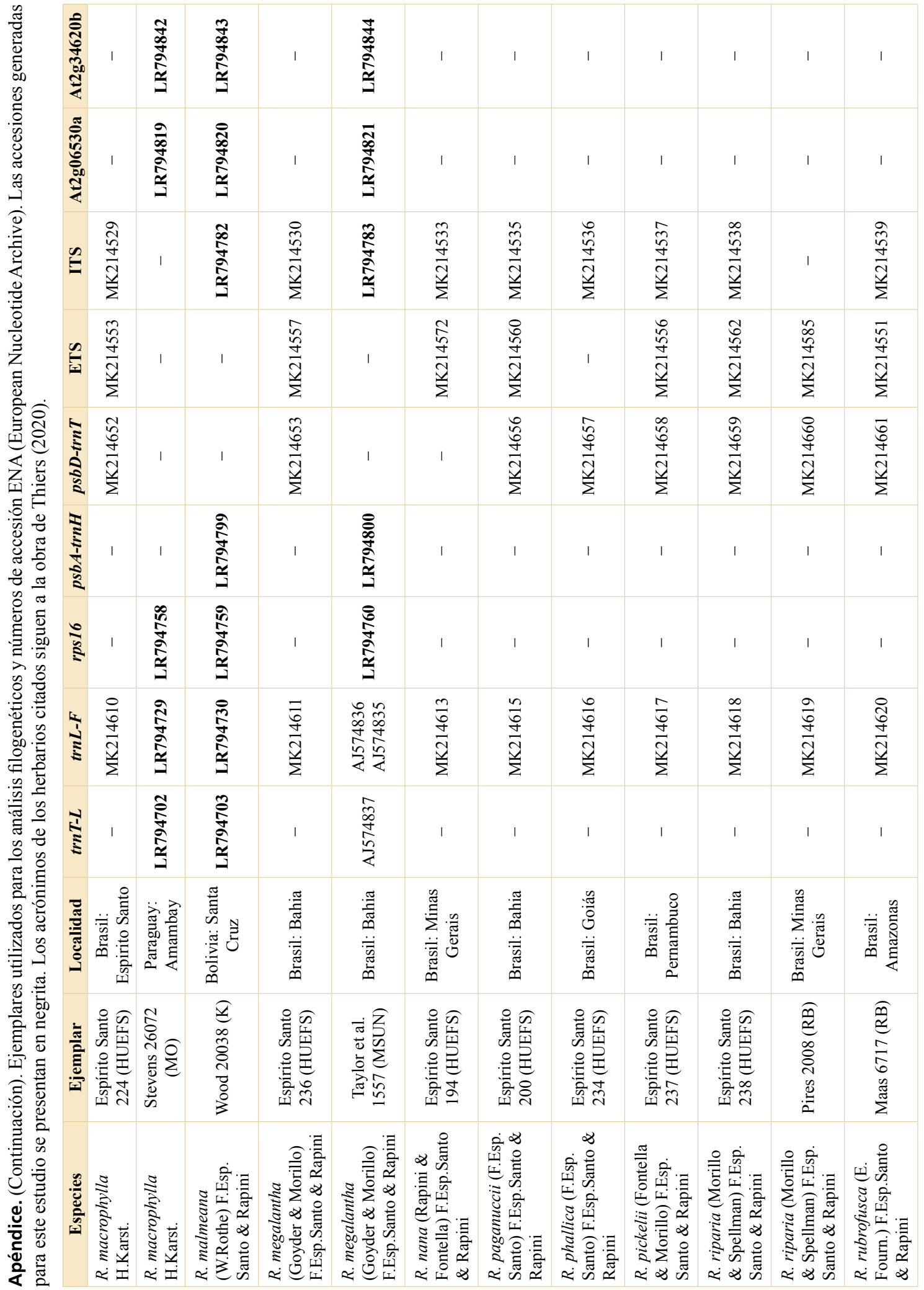




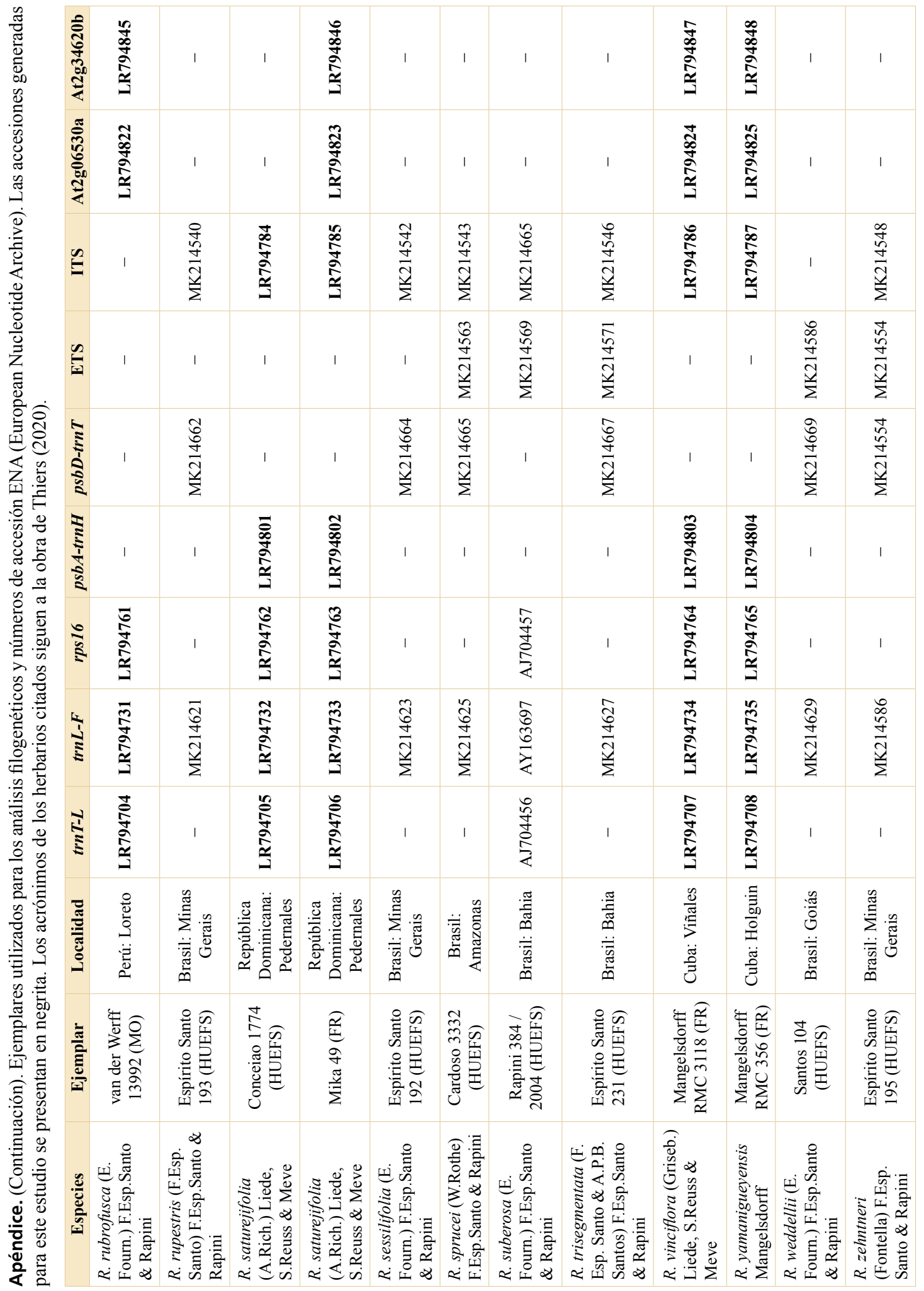

